\title{
Atribuições do enfermeiro no incentivo e orientações a puérpera sobre a importância do aleitamento materno exclusivo
}

The nurse's duties in encouraging and giving guidance to the puerperal woman about the importance of exclusive breastfeeding

Deberes de la enfermera de incentivar y orientar a la puérpera sobre la importancia de la lactancia materna exclusiva

Airton César Leite

ORCID: https://orcid.org/0000-0001-7184-8488 Centro Universitário Santo Agostinho, Brasil E-mail: ainton.cesar2014@gmail.com

Mariana Pereira Barbosa Silva ORCID: https://orcid.org/0000-0003-0852-8099 Universidade Estadual do Piauí, Brasil E-mail: marianapbsilvaa@gmail.com Rayssa Stéfani Sousa Alves ORCID: https://orcid.org/0000-0002-9666-675X Pontifícia Universidade Católica de Goiás, Brasil E-mail: rayssastefani02@gmail.com

Marciele de Lima Silva

ORCID: https://orcid.org/0000-0003-2827-5316 Instituto de Educação Superior da Paraíba, Brasil E-mail: marcieledelsilva@gmail.com

Lorena Mayara Hipólito Feitosa ORCID: https://orcid.org/0000-0002-3643-3436 Universidade Federal do Piauí, Brasil E-mail: lorena_mayara@hotmail.com

Reberson do Nascimento Ribeiro ORCID: https://orcid.org/0000-0003-2644-9917 Centro Universitário UNIFACID, Brasil E-mail: rebersonsrn98@gmail.com

Laisa Fernanda dos Anjos Gomes ORCID: https://orcid.org/0000-0002-2814-0844

Centro Universitário Santo Agostinho, Brasil E-mail: izanandamh@hotmail.com

Maria Clara de Carvalho Freire Fernandes ORCID: https://orcid.org/0000-0002-4924-0457

Centro Universitário Santo Agostinho, Brasil

E-mail: clarafernandesthe@gmail.com

Joana Maria Santana Pinheiro ORCID: https://orcid.org/0000-0003-4991-5730

Centro Universitário Santo Agostinho, Brasil E-mail: joanasantana608@gmail.com

Kelly Cristina Rodrigues do Bonfim ORCID: https://orcid.org/0000-0001-6405-5076 Centro Universitário Santo Agostinho, Brasil E-mail: kellycrisrdg@gmail.com

Maria Rosana Ribeiro de Paiva ORCID: https://orcid.org/0000-0002-0849-6886 Centro Universitário Santo Agostinho, Brasil E-mail: rosanaribeiro569@gmail.com

Nádia Domingas da Silva Santos ORCID: https://orcid.org/0000-0003-2325-6634 Centro Universitário Santo Agostinho, Brasil E-mail: nadiaumb@gmail.com

Klismann Walles Soares do Nascimento ORCID: https://orcid.org/0000-0002-2513-2558 Centro Universitário Santo Agostinho, Brasil E-mail: wallesklismann@gmail.com 


\section{Resumo}

Analisar as evidências científicas acerca das atribuições do enfermeiro no incentivo e orientações a puérpera sobre a importância do aleitamento materno exclusivo. Trata de uma revisão bibliográfica do método revisão integrativa da literatura, realizado nos meses de setembro e outubro de 2020. A busca efetuou-se, através - BVS, utilizando as bases de dados LILACS, BDENF, MEDLINE, e por meio do Portal Google Acadêmico, aderindo-se através dos descritores/palavras chaves: "Cuidados de enfermagem", "Puérpera", "Aleitamento materno", cruzados com o operador booleando "AND". Os critérios de inclusão estabelecidos foram: artigos originais disponibilizados na íntegra, completos, que abrangessem a temática e na forma online, publicados nos idioma português, inglês e espanhol. Os critérios de exclusão estabelecidos na seleção foram: artigos incompletos, artigos duplicados, teses, dissertações, monografias e manuais. Os profissionais de saúde têm uma função relevante na promoção do aleitamento materno, atuando no incentivo e manejo da prática para amamentar. O sucesso da amamentação ocorre através de uma relação harmoniosa do enfermeiro e gestante, assim o papel primordial do enfermeiro é esclarecer as dúvidas sobre importância da amamentação exclusiva, ademais auxiliar nas possíveis dificuldades que venha a enfrentar. A enfermagem tem grande importância na ampliação de estratégias para promover o aleitamento materno e auxiliar na desmistificação e na quebra desses paradigmas. Nesse contexto, o enfermeiro assume o seu papel de educador, orientador e incentivador das práticas de aleitamento materno e, também, garantir a assistência multidisciplinar à mulher e à criança durante o primeiro ano de vida.

Palavras-chave: Cuidados de enfermagem; Puérpera; Aleitamento materno.

\section{Abstract}

To analyze the scientific evidence about the nurse's duties in encouraging and providing guidance to the puerperal woman about the importance of exclusive breastfeeding. This is a bibliographic review of the integrative literature review method, carried out in the months of September and October 2020. The search was carried out, through - VHL, using the LILACS, BDENF, MEDLINE databases, and through the Portal Google Scholar, adhering through the descriptors: "Nursing care", "Puérpera", "Exclusive breastfeeding", crossed with the operator by typing "AND". The 
inclusion criteria established were: original articles made available in full, complete, covering the theme and in the online form, published in Portuguese, English and Spanish. The exclusion criteria established in the selection were: incomplete articles, duplicate articles, theses, dissertations, monographs and manuals. Health professionals have a relevant role in promoting breastfeeding, working to encourage and manage the practice of breastfeeding. The success of breastfeeding occurs through a harmonious relationship between the nurse and the pregnant woman, so the primary role of the nurse is to clarify doubts about the importance of exclusive breastfeeding, in addition to assist in the possible difficulties that he may face. Nursing is of great importance in expanding strategies to promote breastfeeding and assist in demystifying and breaking these paradigms. In this context, the nurse assumes his role as an educator, advisor and promoter of breastfeeding practices and, also, to guarantee multidisciplinary assistance to women and children during the first year of life.

Keywords: Nursing care; Postpartum; Breastfeeding.

\section{Resumen}

Analizar la evidencia científica sobre los deberes de la enfermera de incentivar y orientar a la puérpera sobre la importancia de la lactancia materna exclusiva. Se trata de una revisión bibliográfica del método de revisión integrativa de la literatura, realizada en los meses de septiembre y octubre de 2020. La búsqueda se realizó, a través de - BVS, utilizando las bases de datos LILACS, BDENF, MEDLINE, y a través del Portal. Google Scholar, adhiriéndose a través de los descriptores: "Atención de enfermería", "Puérpera", "Lactancia materna exclusiva", cruzados con el operador escribiendo "Y". Los criterios de inclusión establecidos fueron: artículos originales disponibles en su totalidad, completos, que cubran la temática y en forma online, publicados en portugués, inglés y español. Los criterios de exclusión establecidos en la selección fueron: artículos incompletos, artículos duplicados, tesis, disertaciones, monografías y manuales. Los profesionales de la salud tienen un rol relevante en la promoción de la lactancia materna, trabajando para incentivar y gestionar la práctica de la lactancia materna. El éxito de la lactancia materna se da a través de una relación armoniosa entre la enfermera y la gestante, por lo que la función primordial de la enfermera es aclarar dudas sobre la importancia de la lactancia materna exclusiva, además de ayudar en las posibles dificultades que pueda enfrentar. La enfermería es de gran importancia para ampliar las estrategias para promover la lactancia materna y ayudar a desmitificar y romper estos paradigmas. En este contexto, la enfermera asume su rol de educadora, asesora y promotora de las prácticas de lactancia materna y, además, de garantizar la asistencia multidisciplinaria a mujeres y niños durante el primer año de vida.

Palabras clave: Cuidado de enfermeira; Posparto; Amamantamiento.

\section{Introdução}

A maternidade marca uma nova fase na vida da mulher, em função disso, a experiência de gerar e ter um filho promove reações, sentimentos, fantasias, expectativas que são fundamentais para a prática da amamentação exclusiva, o ato de amamentar é muito mais do que um evento biológico e fisiológico. Ao questionar o que significa a experiência de amamentar para uma mulher a colocamos diante de um fenômeno existencial e não puramente biológico, uma vez que sua vivência é perpassada pela sua percepção, interpretação e atribuição de significados, dentro da sua existência (Brant, Affonso, \& Vargas, 2009).

O leite materno é caracterizado como o alimento adequado para a criança nos primeiros meses de vida, sendo considerado como uma das principais ações para redução da morbimortalidade infantil e uma das maneiras mais eficientes de atenção aos aspectos nutricionais, imunológicos, psicológicos e para o desenvolvimento da criança em seu primeiro ano. Segundo a Organização Mundial de Saúde e o Ministério da Saúde, a amamentação é importante porque no leite materno estão presentes todos os nutrientes essenciais para o crescimento e desenvolvimento da criança, como as proteínas, vitaminas e gorduras (Siqueira, Santos, \& Santos, 2017).

O aleitamento materno é uma das maneiras mais eficientes de atender os aspectos nutricionais, imunológicos e psicológicos da criança em seu primeiro ano de vida, sendo uma prática natural e eficaz, que favorece o vínculo mãe-filho quando o ato de amamentar é bem vivenciado pelas mães. É um ato cujo sucesso depende de fatores históricos, sociais, culturais, e psicológicos da puérpera, depende de compromisso e conhecimento técnico-científico dos profissionais de saúde envolvidos na promoção, incentivo e do apoio ao aleitamento materno. Amamentar significa proteger a saúde do bebê de doenças como diarréia, distúrbios respiratórios, otites e infecção urinária e, ao mesmo tempo, o bebê que é amamentado 
conforme o recomendado tem menos chance de desenvolver diabetes, hipertensão e doenças cardiovasculares. Para as mães, proporciona a redução do sangramento após o parto, diminuição da incidência de anemia, câncer de ovário e mama (Carvalho, Carvalho, \& Magalhães, 2011).

O aleitamento materno exclusivo é o processo pelo qual o bebê recebe leite materno de sua mãe, nutriz ou leite materno extraído, sem que haja a inserção de nenhum outro líquido ou sólido em sua dieta, exceto vitaminas, complementos minerais ou medicamentos. Além de ser o mais completo alimento para o bebê, o leite materno age como agente imunizador, contribui para o desenvolvimento da criança no aspecto psicológico, tem a vantagem técnica por ser operacionalmente simples, possui custo financeiro baixo, tem papel protetor a mulher contra câncer ovariano e mama, auxilia na involução uterina, atrasa a volta da fertilidade e aperfeiçoa a mulher em seu papel de mãe (Barbosa, Santos, Moraes, Rizzardi, \& Corrêa, 2015).

Dessa forma, o aleitamento materno é mais que um meio de prevenção de patologias é a forma de relação mais intima entre mãe e filho onde ambos ganham com essa interação, da qual promove benefícios físicos e psíquicos para lactante e para o lactente evitam problemas nutricionais e infecções, em seu estado fisiológico, também acontecem vantagens como desenvolvimento emocional e cognitivo. $\mathrm{O}$ aleitamento materno exclusivo proporciona ao bebê todas as condições para que cresça e se desenvolva adequadamente até o sexto mês não havendo a necessidade da introdução de qualquer outro tipo de alimento, sendo uma fonte importante de proteínas nos dois primeiros anos de vida, não é diluído, não se contamina, está sempre pronto e fresco. Crianças amamentadas ao seio têm menor risco de desnutrição e outros tipos de desenvolvimento de doenças, por isso o leite materno é o ideal para o bebê (Barbosa, Santos, Moraes, Rizzardi, \& Corrêa, 2015).

Nesse sentido, o leite materno pode ser considerado, atualmente, o alimento ideal para o lactente, em especial nos seis primeiros meses de vida, com benefícios superiores aos demais leites, sua justificativa baseia-se no fato dele ser rico em gorduras, minerais, vitaminas, enzimas e imunoglobulinas. Além disso, possui vantagens nutritivas, inclusive por promover o crescimento e desenvolvimento, bem como por influenciar no futuro desempenho escolar da criança. $\mathrm{O}$ aleitamento materno previne infecções gastrintestinais, respiratórias e urinárias; além de ter um efeito protetor sobre as alergias, o leite materno faz com que os bebês tenham uma melhor adaptação a outros alimentos. Em longo prazo, pode-se referir também à importância do aleitamento materno na prevenção da diabetes e de linfomas (Barbosa, Santos, Moraes, Rizzardi, \& Corrêa, 2015).

A Organização Mundial da Saúde e o Ministério da Saúde preconizam o aleitamento materno exclusivo até o sexto mês de vida da criança, atribuindo-lhe a seguinte definição: "receber apenas o leite proveniente de sua mãe ou de bancos de leite humano, e nenhum outro líquido ou sólido com exceção de vitaminas, minerais e medicamentos", sendo que após o sexto mês recomenda-se incluir juntamente com a amamentação, alimentos complementares até os dois anos de idade.

O aleitamento materno é a estratégia que mais previne mortes infantis, além de promover a saúde física, mental e psíquica da criança. Estima-se que a amamentação tem o potencial de reduzir em $13 \%$ as mortes em crianças menores de 5 anos, assim como em 19 a $22 \%$ as mortes neonatais, se praticada na primeira hora de vida. Nesse contexto, O profissional de enfermagem tem um papel fundamental no AME, pois deve incentivar a promoção e apoio ao aleitamento materno, bem como, compreender o processo do aleitamento no contexto sociocultural e familiar (Costa, Queiroz, Queiroz, Ribeiro, \& Fonseca, 2013).

Assim, o enfermeiro deve identificar as oportunidades que podem assegurar a educação sobre a prática de amamentação, dentro de um diagnóstico precoce e um tratamento a tempo adequado, contribuindo com o desenvolvimento populacional, não somente em uma prestação de assistência, mas também na promoção e educação a saúde. A enfermagem neste momento entra como o reconhecedor dos processos que podem dificultar a amamentação da criança, sendo de grande consequência para a mãe e para a criança. Desse modo, a enfermagem contribui com a orientação e esclarecimentos integrados, humanizados e com respeito, ajudando na superação de inseguranças, dificuldades e formação familiar (Santos, Santos, \& Oliveira, 2019). 
Além disso, o enfermeiro pode sanar as dúvidas, ensinar como amamentar, desmistificar medos, e ajudar a mãe a compreender o seu papel nesta fase importante de vida do bebê. Para tanto é necessário que o enfermeiro busque interagir com esta mulher, conhecer as dificuldades da mesma e informá-la sobre a importância de adotar uma prática saudável de aleitamento materno. Desta forma, o profissional precisa estar preparado para prestar uma assistência solidária, integral e eficaz, respeitando o saber, a história de vida de cada mulher para que esta possa superar seus medos, dificuldades e inseguranças (Santos, Santos, \& Oliveira, 2019).

Diante da problemática em discussão, surge como questão norteadora do estudo: "Quais as atribuições do enfermeiro no incentivo e orientações a puérpera sobre a importância do aleitamento materno exclusivo"?

A realização do estudo relacionado à temática, é essencial para a construção do conhecimento, pois, o estudo possibilita a sociedade acadêmica e cientifica a ampliar o conhecimento sobre as atribuições do enfermeiro no incentivo e orientações a puérpera sobre a importância do aleitamento materno exclusivo, a pesquisa aborda uma questão que deve ser bastante trabalhada e discutida pela equipe de saúde, no sentido de melhorar significativamente a assistência prestada a essas pacientes. Desse modo, o estudo trará contribuições importantes para a comunidade científica e para a sociedade, na medida em que acrescentará as evidências científicas discussões relevantes a respeito dessa temática.

Assim, o objetivo do estudo é analisar as evidências científicas acerca das atribuições do enfermeiro no incentivo e orientações a puérpera sobre a importância do aleitamento materno exclusivo.

\section{Metodologia}

O presente estudo trata de uma revisão bibliográfica do método revisão integrativa da literatura, realizado nos meses de setembro e outubro de 2020. Sendo uma ferramenta de investigação que permite à procura, a avaliação crítica e a síntese das evidências disponíveis sobre o tema investigado, em que o produto final é o estado do conhecimento, a implementação de intervenções efetivas na prestação de cuidados e na redução de custos. Além disso, permite a identificação de fragilidades, que poderão conduzir ao desenvolvimento de futuras investigações (Sousa, Marques-Vieira, Severino, \& Antunes, 2017).

A revisão configura-se, portanto, como um tipo de revisão da literatura que reúne achados de estudos desenvolvidos mediante diferentes metodologias, permitindo aos revisores sintetizar resultados sem ferir a filiação epistemológica dos estudos empíricos incluídos. Para que esse processo se concretize de maneira lógica, isenta de desatinos epistemológicos, a revisão requer que os revisores procedam à análise e à síntese dos dados primários de forma sistemática e rigorosa (Soares et al., 2014).

Esse instrumento de estudo requer um padrão de excelência quanto ao rigor metodológico para que seu produto possa trazer contribuições significativas para a ciência e para a prática clínica. A preservação deste padrão requer o uso de métodos que garantam a análise precisa, objetiva e completa do tema revisado; o suporte teórico para analisar resultados, métodos, sujeitos e variáveis dos estudos primários; a provisão de todas as informações contidas nos estudos revisados e não apenas os principais resultados, de modo a informar o leitor sem o sobrecarregar com informações desnecessárias (Soares et al., 2014).

O processo de revisão da literatura requer a elaboração de uma síntese pautada em diferentes tópicos, capazes de criar uma ampla compreensão sobre o conhecimento. A revisão da literatura é um primeiro passo para a construção do conhecimento científico, pois é através desse processo que novas teorias surgem, bem como são reconhecidas lacunas e oportunidades para o surgimento de pesquisas num assunto específico (Botelho, Cunha, \& Macedo, 2011).

A revisão integrativa permite que o leitor reconheça os profissionais que mais investigam determinado assunto, separar o achado científico de opiniões e ideias, além de descrever o conhecimento no seu estado atual, promovendo impacto sobre a prática clínica. Este método de pesquisa proporciona aos profissionais de saúde dados relevantes de um determinado 
assunto, em diferentes lugares e momentos, mantendo-os atualizados e facilitando as mudanças na prática clínica como consequência da pesquisa. Dessa forma, acreditamos que a revisão integrativa é uma ferramenta importante no processo de comunicação dos resultados de pesquisas, facilitando a utilização desses na prática clínica, uma vez que proporciona uma síntese do conhecimento já produzido e fornece subsídios para a melhoria da assistência à saúde (Mendes, Silveira, \& Galvão, 2008).

Fluxograma 1. Fases distintas da revisão integrativa.

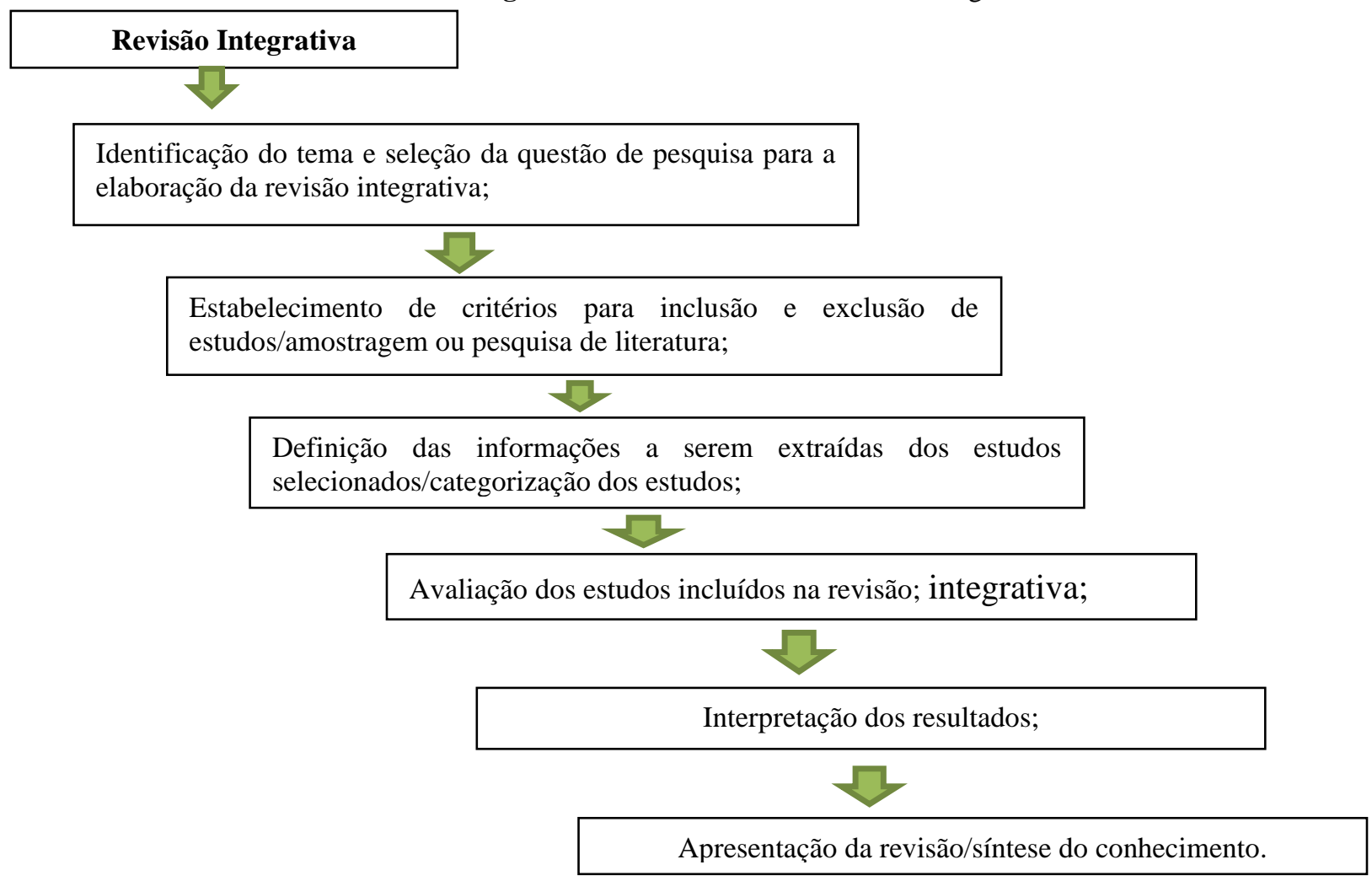

Fonte: Mendes, Silveira, \& Galvão (2008).

A revisão integrativa é um tipo de pesquisa que fornece informações mais amplas de maneira sistemática, ordenada e abrangente, sobre um assunto ou tema, com finalidade de sintetizar resultados obtidos em pesquisa sobre temas ou questões. A definição das informações a serem extraídas dos estudos selecionados por categorização; avaliação dos estudos incluídos; interpretação dos resultados; e apresentação da revisão/síntese do conhecimento (Ercole, Melo, \& Alcoforado, 2015).

Estudo elaborado com abordagem qualitativa tornando-se importante a interpretação por parte do pesquisador com suas opiniões sobre o fenômeno em estudo. Neste tipo de pesquisa destacam-se algumas características como: a pesquisa qualitativa, em geral, ocorre no ambiente natural com coleta direta de dados e o pesquisador é o principal instrumento; os dados coletados são preferencialmente descritivos; a preocupação do processo é predominante em relação à do produto; a análise de dados e informações tende a seguir um processo indutivo (Pereira, Shitsuka, Parreira, \& Shitsuka, 2018).

Estudo a ser realizado nas seguintes etapas: 1- Elaboração da pergunta norteadora; 2- Busca nas bases de dados e amostragem; 3- Coleta de dados, 4- Análise críticas dos estudos organizada e organização dos dados (Souza, Silva, \& Carvalho, 2010). 
Research, Society and Development, v. 10, n. 1, e32910111736, 2021

(CC BY 4.0) | ISSN 2525-3409 | DOI: http://dx.doi.org/10.33448/rsd-v10i1.11736

Para responder à questão norteadora do estudo: "Quais as atribuições do enfermeiro no incentivo e orientações a puérpera sobre a importância do aleitamento materno exclusivo"? aplicou-se os descritores/palavras chaves: "Cuidados de enfermagem", "Puérpera", "Aleitamento Materno".

A busca efetuou-se, através da Plataforma da Biblioteca Virtual em Saúde - BVS, utilizando as bases de dados Literatura Latino-Americana e do Caribe em Ciências da Saúde (LILACS), Base de Dados de Enfermagem (BDENF), Medical Literature Analysis and Retrievel System Online (MEDLINE), e por meio do Portal Google Acadêmico, aderindo-se através dos descritores: "Cuidados de enfermagem", "Puérpera", "Aleitamento Materno", cruzados com o operador booleando "AND".

Os critérios de inclusão estabelecidos foram: artigos originais disponibilizados na íntegra, completos, que abrangessem a temática e na forma online, publicados nos idiomas português, inglês e espanhol. Os critérios de exclusão estabelecidos na seleção foram: artigos incompletos, artigos duplicados, teses, dissertações, monografias e manuais. No início da pesquisa obteve-se 7992 publicações, após a aplicação dos critérios de inclusão e exclusão totalizou-se parcialmente 110 artigos, depois de uma leitura mais precisa, aderiu-se um total final de 33 publicações de acordo para serem trabalhadas no estudo.

O presente fluxograma representado abaixo, caracteriza a estratégia de coleta de dados utilizada pelos autores, no sentido de detalhar as principais evidencias encontradas no estudo. 
Fluxograma 2. Estratégia de Busca, Bases de dados, 2020.

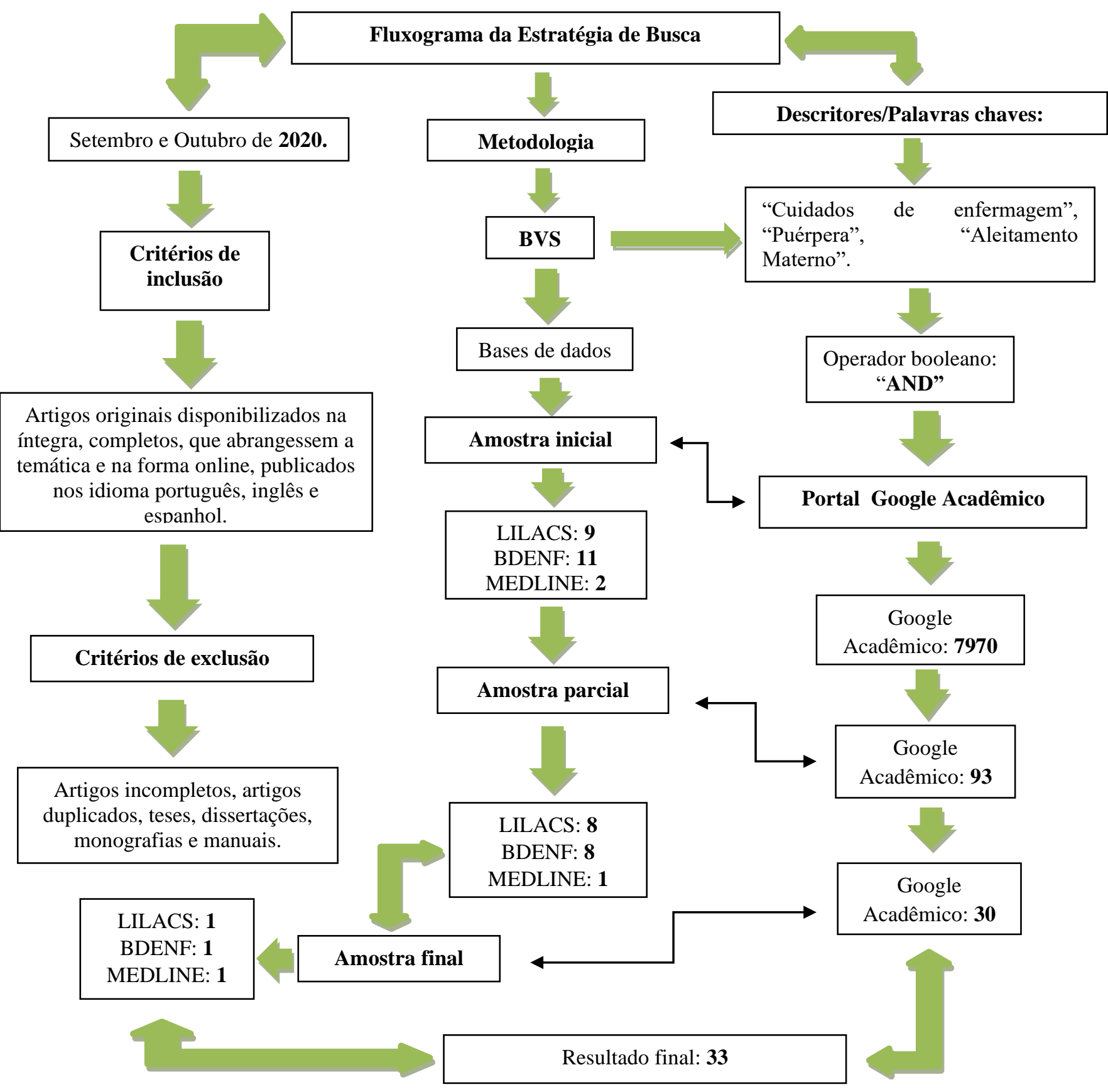

Fonte: Dados da pesquisa (2020)

No Fluxograma 2 estão expostos, estratégia de busca, bases de dados, período de realização do estudo, critérios de inclusão e exclusão, amostra inicial, parcial e final, de acordo com a quantidade de artigos que irão compor os resultados do estudo.

O presente estudo assegura os aspectos éticos, garantindo a autoria dos artigos pesquisados, utilizando para as citações e referências dos autores as normas APA. Os preceitos éticos estabelecidos no que se refere a zelar pela legitimidade das informações, privacidade e sigilo das informações, quando necessárias, tornando os resultados desta pesquisa públicos. Os pesquisadores buscaram a legitimidade e fidelidade nas citações dos autores seja nas citações diretas ou parafraseadas no estudo. 


\section{Resultados e Discussão}

Diante dos resultados obtidos no estudo por meio da estratégia de busca, os autores delinearam variáveis para melhor descrever as evidências encontradas na pesquisa. O quadro a seguir caracteriza os artigos com base nas variáveis propostas: número do artigo, base de dados, autor e ano de publicação, título, objetivo, e principais conclusões importantes.

Quadro 1. Caracterização dos artigos conforme número, base de dados, título, objetivo e principais conclusões importantes. Teresina - PI, Brasil, 2020.

\begin{tabular}{|c|c|c|c|c|c|}
\hline $\mathbf{N}^{\circ}$ & $\begin{array}{c}\text { Bases de } \\
\text { dados }\end{array}$ & Título & $\begin{array}{c}\text { Autor e } \\
\text { ano }\end{array}$ & Objetivo & Conclusões importantes \\
\hline 1 & $\begin{array}{l}\text { GOOGLE } \\
\text { ACADÊMI } \\
\text { CO }\end{array}$ & $\begin{array}{l}\text { Cuidado de enfermagem } \\
\text { sobre a importância do } \\
\text { Aleitamento Materno } \\
\text { exclusivo: percepção de } \\
\text { puérperas. }\end{array}$ & $\begin{array}{c}\text { Ferreira } \\
\text { Junior et al., } \\
2016 .\end{array}$ & $\begin{array}{l}\text { Investigar a percepção de } \\
\text { puérperas do cuidado de } \\
\text { enfermagem prestado no } \\
\text { pré-natal sobre a } \\
\text { importância do aleitamento } \\
\text { materno exclusivo. }\end{array}$ & $\begin{array}{l}\text { O enfermeiro tem importante papel nas } \\
\text { atividades de prevenção e promoção do } \\
\text { aleitamento materno, devendo trabalhar } \\
\text { com visitas domiciliares, palestras, } \\
\text { grupos de apoio e aconselhamento da } \\
\text { amamentação exclusiva. }\end{array}$ \\
\hline 2 & $\begin{array}{l}\text { GOOGLE } \\
\text { ACADÊMI } \\
\text { CO }\end{array}$ & $\begin{array}{l}\text { Incentivo à amamentação } \\
\text { exclusiva na perspectiva } \\
\text { das puérperas. }\end{array}$ & $\begin{array}{l}\text { Brant, } \\
\text { Affonso, } \\
\text { Vargas, } \\
2009 .\end{array}$ & 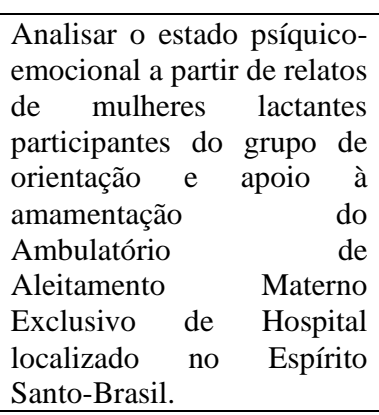 & $\begin{array}{l}\text { A atuação de equipe multidisciplinar } \\
\text { em grupos de orientação e apoio à } \\
\text { amamentação exclusiva é importante } \\
\text { tanto para as mães quanto para seus } \\
\text { familiares, criando espaços de trocas } \\
\text { tanto informativas quanto afetivas, nas } \\
\text { quais eles possam esclarecer dúvidas, } \\
\text { dividir experiências, construir laços de } \\
\text { amizades. }\end{array}$ \\
\hline 3 & $\begin{array}{l}\text { GOOGLE } \\
\text { ACADÊMI } \\
\text { CO }\end{array}$ & $\begin{array}{l}\text { Atuação do enfermeiro } \\
\text { no PSF sobre aleitamento } \\
\text { materno. }\end{array}$ & $\begin{array}{c}\text { Amorim, } \\
\text { Andrade, } \\
2009 .\end{array}$ & $\begin{array}{l}\text { Discutir sobre a importância } \\
\text { do aleitamento materno e } \\
\text { suas contribuições para a } \\
\text { redução do desmame } \\
\text { precoce, desnutrição e do } \\
\text { índice de morbimortalidade } \\
\text { infantil melhorando } \\
\text { efetivamente a qualidade de } \\
\text { vida dos lactentes e o papel } \\
\text { do enfermeiro do PSF neste } \\
\text { processo. }\end{array}$ & $\begin{array}{l}\text { O enfermeiro é o profissional que, seja } \\
\text { na rede básica, hospitalar ou } \\
\text { ambulatorial, deve estar preparado para } \\
\text { lidar e direcionar uma demanda } \\
\text { diversificada, principalmente quando se } \\
\text { tratar de questões de ordem da mulher } \\
\text { nutriz, deve ser capaz de identificar e } \\
\text { oportunizar momentos educativos, } \\
\text { facilitando a amamentação, o } \\
\text { diagnóstico e o tratamento adequados. }\end{array}$ \\
\hline 4 & $\begin{array}{l}\text { GOOGLE } \\
\text { ACADÊMI } \\
\text { CO }\end{array}$ & $\begin{array}{l}\text { Influência da assistência } \\
\text { de enfermagem na } \\
\text { prática da amamentação } \\
\text { no puerpério imediato. }\end{array}$ & $\begin{array}{l}\text { Batista, } \\
\text { Farias, Melo, } \\
2013 .\end{array}$ & $\begin{array}{l}\text { Compreender a influência } \\
\text { da assistência de } \\
\text { enfermagem, como suporte } \\
\text { social, em relação ao } \\
\text { aleitamento materno, no } \\
\text { município de Cajazeiras } \\
\text { (PB). }\end{array}$ & $\begin{array}{l}\text { O aleitamento materno é considerado a } \\
\text { nutrição ideal para todos os bebês, } \\
\text { sendo indiscutível sua importância para } \\
\text { a saúde da criança, uma vez que oferece } \\
\text { proteção imunológica. }\end{array}$ \\
\hline 5 & $\begin{array}{l}\text { GOOGLE } \\
\text { ACADÊMI } \\
\text { CO }\end{array}$ & $\begin{array}{lr}\text { Importância } & \text { da } \\
\text { enfermagem frente à } \\
\text { assistência primária ao } \\
\text { aleitamento } & \text { materno } \\
\text { exclusivo na atenção } \\
\text { básica. }\end{array}$ & $\begin{array}{c}\text { Lustosa, } \\
\text { Lima, } 2020 .\end{array}$ & $\begin{array}{l}\text { Verificar a prática dos } \\
\text { profissionais } \\
\text { enfermagem relacionada ao } \\
\text { aleitamento materno, no } \\
\text { período gravídico e } \\
\text { puerperal especificamente. }\end{array}$ & $\begin{array}{l}\text { O AME é fundamental para a saúde do } \\
\text { bebê, pois oferta tudo o que é } \\
\text { necessário para o bom crescimento e } \\
\text { desenvolvimento deste. A sua } \\
\text { promoção deve estar inserida no rol das } \\
\text { ações prioritárias da saúde do binômio } \\
\text { mãe/bebê, pois esta prática proporciona } \\
\text { mais saúde a criança, além de funcionar } \\
\text { como uma vacina natural, não } \\
\text { apresentando nenhum risco de } \\
\text { contaminação ao bebê e tem função de } \\
\text { estimulação. }\end{array}$ \\
\hline
\end{tabular}




\begin{tabular}{|c|c|c|c|c|c|}
\hline 6 & $\begin{array}{l}\text { GOOGLE } \\
\text { ACADÊMI } \\
\text { CO }\end{array}$ & $\begin{array}{l}\text { Ações desencadeadas } \\
\text { pelo enfermeiro para } \\
\text { promoção do aleitamento } \\
\text { materno e prevenção do } \\
\text { desmame precoce. }\end{array}$ & $\begin{array}{l}\text { Santos, } \\
\text { Santos, } \\
\text { Siqueira, } \\
2017 .\end{array}$ & $\begin{array}{l}\text { Descrever as ações } \\
\text { desencadeadas }\end{array} \begin{array}{l}\text { pelo } \\
\text { enfermeiro para promoção } \\
\text { do aleitamento materno e } \\
\text { prevenção do desmame } \\
\text { precoce. }\end{array}$ & $\begin{array}{l}\text { O AME é importante não só para o } \\
\text { bebê, mas também para a genitora. O } \\
\text { leite materno oferecido exclusivamente } \\
\text { durante os seis primeiros meses de vida, } \\
\text { conforme preconizado pelo MS, } \\
\text { promove diversos benefícios, de forma } \\
\text { que esta prática deve ser encorajada. }\end{array}$ \\
\hline 7 & $\begin{array}{l}\text { GOOGLE } \\
\text { ACADÊMI } \\
\text { CO }\end{array}$ & $\begin{array}{l}\text { Conhecimento r de } \\
\text { puérperas } \\
\text { amamentação exclusiva. }\end{array}$ & $\begin{array}{l}\text { Silva et al., } \\
\quad 2014 .\end{array}$ & \begin{tabular}{lr}
\multicolumn{2}{l}{ Identificar o conhecimento } \\
das puérperas & sobre \\
aleitamento & materno \\
exclusivo. &
\end{tabular} & $\begin{array}{l}\text { É importante que os profissionais da } \\
\text { saúde, e em especial o enfermeiro, } \\
\text { pratiquem o cuidado integral, } \\
\text { valorizando todos os períodos no } \\
\text { acompanhamento da mulher, desde o } \\
\text { pré-natal até o pós-parto tardio, nos } \\
\text { quais podem ocorrer dificuldades } \\
\text { relacionadas ao aleitamento materno. } \\
\text { Fora do contexto hospitalar nas } \\
\text { unidades básicas de saúde, com o apoio } \\
\text { da Equipe de Estratégia Saúde da } \\
\text { Família e por meio das estratégias da } \\
\text { Rede Amamenta e Alimenta Brasil, } \\
\text { pode-se promover e talvez assegurar o } \\
\text { aleitamento por um período maior. }\end{array}$ \\
\hline 8 & $\begin{array}{l}\text { GOOGLE } \\
\text { ACADÊMI } \\
\text { CO }\end{array}$ & $\begin{array}{ll}\text { A importância } & \text { da } \\
\text { assistência } & \text { de } \\
\text { enfermagem } & \text { no } \\
\text { aleitamento materno. } & \end{array}$ & $\begin{array}{l}\text { Carvalho, } \\
\text { Carvalho, } \\
\text { Magalhães, } \\
\quad 2011 .\end{array}$ & $\begin{array}{l}\text { Descrever a importância da } \\
\text { assistência de enfermagem } \\
\text { para o alcance do sucesso } \\
\text { no aleitamento materno, } \\
\text { bem como a necessidade e } \\
\text { importância } \\
\text { amamentação da } \\
\text { orientações básicas a } \\
\text { puérpera e familiares. }\end{array}$ & $\begin{array}{l}\text { É fundamental que os pais e familiares } \\
\text { tenham conhecimento da importância } \\
\text { do aleitamento materno para o bom } \\
\text { desenvolvimento da criança. Cabe aos } \\
\text { profissionais de saúde devidamente } \\
\text { capacitados, orientar e apoiar as mães } \\
\text { que sofrem algum tipo de intercorrência } \\
\text { na lactação para que haja um menor } \\
\text { índice de desmame causado por fatores } \\
\text { passiveis de prevenção. }\end{array}$ \\
\hline 9 & $\begin{array}{l}\text { GOOGLE } \\
\text { ACADÊMI } \\
\text { CO }\end{array}$ & $\begin{array}{l}\text { Prevalência de práticas } \\
\text { educativas acerca do } \\
\text { aleitamento } \text { materno } \\
\text { exclusivo (AME) em } \\
\text { Cuiabá-MT. }\end{array}$ & $\begin{array}{c}\text { Barbosa et } \\
\text { al., } 2015 .\end{array}$ & $\begin{array}{l}\text { Descrever a prevalência das } \\
\text { práticas educativas em } \\
\text { saúde sobre o aleitamento } \\
\text { materno exclusivo (AME) } \\
\text { no Município de Cuiabá - } \\
\text { MT nos meses de julho a } \\
\text { dezembro de } 2012 \text {. }\end{array}$ & $\begin{array}{l}\text { A educação em saúde pode ser um } \\
\text { instrumento indispensável, pois permite } \\
\text { desenvolver atividades direcionadas aos } \\
\text { princípios de educar, facilitando, com } \\
\text { isso, a sensibilização das mães para a } \\
\text { tomada de consciência destes valores. }\end{array}$ \\
\hline 10 & $\begin{array}{l}\text { GOOGLE } \\
\text { ACADÊMI } \\
\text { CO }\end{array}$ & $\begin{array}{l}\text { O papel da enfermagem } \\
\text { na orientação do } \\
\text { aleitamento materno } \\
\text { exclusivo. }\end{array}$ & $\begin{array}{c}\text { Ferreira et } \\
\text { al., } 2016 .\end{array}$ & $\begin{array}{l}\text { Retratar a importância da } \\
\text { orientação da enfermagem } \\
\text { no aleitamento materno. }\end{array}$ & $\begin{array}{l}\text { O apoio dos serviços e profissionais de } \\
\text { saúde é de extrema importância para } \\
\text { que o aleitamento materno tenha } \\
\text { sucesso. Ao decorrer das ações } \\
\text { educativas destinadas a mulher e a } \\
\text { criança, deve-se ressaltar a importância } \\
\text { do aleitamento materno exclusivo até os } \\
\text { seis meses, enfatizando os benefícios do } \\
\text { leite materno que protege o bebê de } \\
\text { infecções e alergias, enumerando as } \\
\text { demais vantagens do aleitamento para a } \\
\text { criança e para mãe. }\end{array}$ \\
\hline 11 & $\begin{array}{l}\text { GOOGLE } \\
\text { ACADÊMI } \\
\text { CO }\end{array}$ & $\begin{array}{l}\text { Conhecimento de } \\
\text { primíparas sobre os } \\
\text { benefícios do aleitamento } \\
\text { materno. }\end{array}$ & $\begin{array}{l}\text { Azevedo et } \\
\text { al., } 2010 .\end{array}$ & $\begin{array}{l}\text { Identificar o conhecimento } \\
\text { das primíparas a respeito } \\
\text { dos benefícios do } \\
\text { aleitamento materno para a } \\
\text { mãe e o recém nascido, } \\
\text { desenvolvido na } \\
\text { Maternidade Escola Assis } \\
\text { Chateaubriand - MEAC, } \\
\text { entre os meses de novembro } \\
\text { de } 2006 \text { e janeiro } 2007 \text {. }\end{array}$ & $\begin{array}{l}\text { A prática do aleitamento materno (AM) } \\
\text { não se restringe apenas ao binômio mãe } \\
\text { e filho, mas possui consequências a } \\
\text { nível de sociedade, pois uma vez a } \\
\text { criança adequadamente nutrida tem-se } \\
\text { repercussões na redução dos índices de } \\
\text { morbimortalidade neonatal e infantil. }\end{array}$ \\
\hline 12 & $\begin{array}{l}\text { GOOGLE } \\
\text { ACADÊMI } \\
\text { CO }\end{array}$ & $\begin{array}{l}\text { Enfermeiro como ator } \\
\text { social incentivador do } \\
\text { aleitamento materno: } \\
\text { perspectivas de mulheres } \\
\text { gestantes acerca do papel } \\
\text { da amamentação. }\end{array}$ & $\begin{array}{l}\text { Monteiro, } \\
\text { Pereira, } \\
2019 .\end{array}$ & $\begin{array}{l}\text { Identificar os métodos de } \\
\text { incentivo do enfermeiro } \\
\text { frente ao aleitamento } \\
\text { materno exclusivo no } \\
\text { município de São Sebastião } \\
\text { - TO. }\end{array}$ & $\begin{array}{l}\text { O aleitamento materno é considerado } \\
\text { um dos elementos essenciais ao } \\
\text { crescimento físico, funcional e mental, } \\
\text { como também uma forma de diminuir a } \\
\text { mortalidade materna infantil, } \\
\text { especialmente no primeiro ano de vida. }\end{array}$ \\
\hline
\end{tabular}




\begin{tabular}{|c|c|c|c|c|c|}
\hline 13 & $\begin{array}{l}\text { GOOGLE } \\
\text { ACADÊMI } \\
\text { CO }\end{array}$ & $\begin{array}{l}\text { Importância } r \\
\text { aleitamento } \\
\text { exclusivo. }\end{array}$ & $\begin{array}{c}\text { Costa et al. } \\
2013 .\end{array}$ & $\begin{array}{l}\text { Identificar a produção } \\
\text { cientifica quanto à } \\
\text { importância do aleitamento } \\
\text { materno exclusivo no } \\
\text { período de } 2008 \text { a } 2013 \text {. }\end{array}$ & $\begin{array}{l}\text { A importância do aleitamento materno } \\
\text { na prevenção de defeitos na oclusão dos } \\
\text { dentes, diminui a incidência de caries e } \\
\text { problemas de fala. Ainda possui } \\
\text { proteção contra doenças como diarreia, } \\
\text { pneumonias, infecção de ouvido, } \\
\text { alergias entre muitos outros. trazendo } \\
\text { assim inúmeras vantagens para a } \\
\text { criança se desenvolver forte e saudável, } \\
\text { além de benefícios para a mãe, o pai e a } \\
\text { família. }\end{array}$ \\
\hline 14 & $\begin{array}{l}\text { GOOGLE } \\
\text { ACADÊMI } \\
\text { CO }\end{array}$ & $\begin{array}{l}\text { Amamentação: } \\
\text { influência familiar e o } \\
\text { papel dos profissionais } \\
\text { de saúde. }\end{array}$ & $\begin{array}{l}\text { Prates, } \\
\text { Schmalfuss, } \\
\text { Lipinski, } \\
2014 .\end{array}$ & $\begin{array}{l}\text { Conhecer a influência } \\
\text { familiar na amamentação e } \\
\text { refletir sobre o papel dos } \\
\text { profissionais de saúde nessa } \\
\text { prática. }\end{array}$ & $\begin{array}{l}\text { Os profissionais de saúde devem } \\
\text { aproximar a família das ações que } \\
\text { envolvem a amamentação, de modo a } \\
\text { conhecer os saberes e experiências que } \\
\text { permeiam esta prática e implementar } \\
\text { ações que possam promovê-la, protegê-- } \\
\text { la e apoiá-la. }\end{array}$ \\
\hline 15 & $\begin{array}{l}\text { GOOGLE } \\
\text { ACADÊMI } \\
\text { CO }\end{array}$ & $\begin{array}{l}\text { Orientação profissional e } \\
\text { aleitamento materno } \\
\text { exclusivo. }\end{array}$ & $\begin{array}{c}\text { Bauer et al., } \\
2019 .\end{array}$ & $\begin{array}{lr}\text { Analisar a orientação sobre } \\
\text { amamentação } & \text { durante a } \\
\text { assistência } & \text { gravídico- } \\
\text { puerperal e o desfecho no } \\
\text { aleitamento } \\
\text { exclusivo. }\end{array}$ & $\begin{array}{l}\text { Para incentivar e manter o AME no } \\
\text { contexto dos serviços de saúde, do } \\
\text { primário ao terciário, é necessário } \\
\text { construir o vínculo, valorizar a escuta e } \\
\text { a responsabilização na assistência, } \\
\text { oferecer materiais e promover grupos } \\
\text { de apoio para troca de experiências, a } \\
\text { fim de promover a melhoria do cuidado } \\
\text { conforme as reais necessidades e com } \\
\text { maior resolubilidade, principalmente na } \\
\text { duração do AM. }\end{array}$ \\
\hline 16 & $\begin{array}{l}\text { GOOGLE } \\
\text { ACADÊMI } \\
\text { CO }\end{array}$ & $\begin{array}{ll}\text { A enfermagem } & \text { e a } \\
\text { orientação } & \text { sobre } \\
\text { aleitamento materno. }\end{array}$ & $\begin{array}{l}\text { Santos, } \\
\text { Santos, } \\
\text { Oliveira, } \\
2019 .\end{array}$ & $\begin{array}{l}\text { Compreender a atuação da } \\
\text { enfermagem como } \\
\text { orientador na amamentação. }\end{array}$ & $\begin{array}{l}\text { O enfermeiro é quem mantém a relação } \\
\text { direta com a mãe, juntamente com sua } \\
\text { equipe deve atuar no sentido de } \\
\text { promover o incentivo a amamentação, } \\
\text { conquistando a confiança da mãe e } \\
\text { orientando sobre os cuidados com o } \\
\text { recém-nascido. }\end{array}$ \\
\hline 17 & $\begin{array}{l}\text { GOOGLE } \\
\text { ACADÊMI } \\
\text { CO }\end{array}$ & $\begin{array}{lr}\text { Aleitamento } & \text { materno: } \\
\text { abordagem } & \text { do } \\
\text { enfermeiro } & \text { para } \\
\text { incentivo a essa prática. }\end{array}$ & $\begin{array}{l}\text { Leal, } \\
\text { Skupien, } \\
\text { Ravelli, } \\
2017 .\end{array}$ & $\begin{array}{l}\text { Analisar os problemas } \\
\text { mamários associados à } \\
\text { amamentação } r \text { que } \\
\text { acometem as puérperas } \\
\text { participantes do projeto } \\
\text { Consulta de Enfermagem } \\
\text { no Pré-Natal e Pós-Parto. }\end{array}$ & $\begin{array}{l}\text { É necessário orientar, intervir, } \\
\text { promover e estimular o aleitamento } \\
\text { materno, para que as puérperas estejam } \\
\text { preparadas para realizar o aleitamento } \\
\text { livre de problemas mamários. Portanto, } \\
\text { o cuidado, a orientação e o estímulo da } \\
\text { enfermagem são essenciais para a saúde } \\
\text { materno-infantil e é uma obrigação } \\
\text { esclarecer dúvidas, pois é um direito de } \\
\text { toda mulher amamentar sem dor. }\end{array}$ \\
\hline 18 & $\begin{array}{l}\text { GOOGLE } \\
\text { ACADÊMI } \\
\text { CO }\end{array}$ & $\begin{array}{lr}\text { Criando laços de amor: a } \\
\text { importância } & \text { do } \\
\text { aleitamento } & \text { materno } \\
\text { exclusivo. } & \end{array}$ & $\begin{array}{l}\text { Alencar et } \\
\text { al., } 2019 .\end{array}$ & $\begin{array}{l}\text { Promover ações educativas } \\
\text { para empoderar o grupo de } \\
\text { gestante no manejo da } \\
\text { amamentação. }\end{array}$ & $\begin{array}{l}\text { É imprescindível que os profissionais } \\
\text { de saúde promovam ações } \\
\text { continuamente as quais possam } \\
\text { favorecer o aumento da duração do } \\
\text { aleitamento materno exclusivo, } \\
\text { orientando as mães quanto a } \\
\text { importância da amamentação e } \\
\text { ressaltando os riscos de um desmame } \\
\text { precoce, visto que durante as } \\
\text { intervenções é possível perceber que } \\
\text { muitas mulheres possui dúvidas acerca } \\
\text { do assunto. }\end{array}$ \\
\hline 19 & $\begin{array}{l}\text { GOOGLE } \\
\text { ACADÊMI } \\
\text { CO }\end{array}$ & $\begin{array}{l}\text { Intervenção educacional } \\
\text { em equipes do Programa } \\
\text { de Saúde da Família para } \\
\text { promoção da } \\
\text { amamentação. }\end{array}$ & $\begin{array}{l}\text { Caldeira, } \\
\text { Fagundes, } \\
\text { Aguiar, } \\
2008 .\end{array}$ & 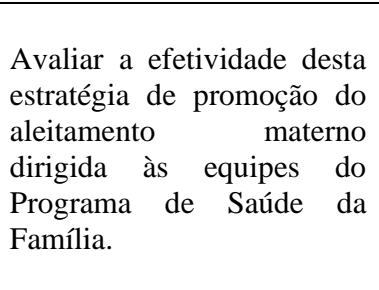 & $\begin{array}{l}\text { A amamentação é uma opção materna } \\
\text { que envolve uma complexa interação de } \\
\text { fatores socioeconômicos, culturais e } \\
\text { psicológicos. Os serviços materno- } \\
\text { infantis também têm importante papel } \\
\text { em sua promoção. Considerando o } \\
\text { papel protetor do aleitamento materno } \\
\text { sobre a morbidade e mortalidade. }\end{array}$ \\
\hline
\end{tabular}




\begin{tabular}{|c|c|c|c|c|c|}
\hline 20 & $\begin{array}{l}\text { GOOGLE } \\
\text { ACADÊMI } \\
\text { CO }\end{array}$ & $\begin{array}{l}\text { A importância da } \\
\text { assistência do enfermeiro } \\
\text { das práticas educativas } \\
\text { no aleitamento materno. }\end{array}$ & $\begin{array}{c}\text { Barroso, } \\
\text { Alves, } 2020 .\end{array}$ & $\begin{array}{l}\text { Descrever a importância das } \\
\text { práticas educativas no } \\
\text { aleitamento materno, } \\
\text { identificar os benefícios } \\
\text { para a saúde da mãe que } \\
\text { amamenta, destacar a } \\
\text { importância nutricional do } \\
\text { leite materno para criança, e } \\
\text { enfatizar as estratégias que } \\
\text { colaboram para aumentar a } \\
\text { adesão das mães no } \\
\text { processo de amamentação. }\end{array}$ & $\begin{array}{l}\text { É de suma importância ressaltar que foi } \\
\text { que o aleitamento materno é a forma } \\
\text { mais íntima de interação entre a mãe e } \\
\text { filho, onde é estabelecido o vínculo } \\
\text { afetivo e de confiança entre ambos. A } \\
\text { promoção da do aleitamento materno é } \\
\text { um componente fundamental de } \\
\text { estratégias entre os cuidados primários } \\
\text { de saúde para a adesão. }\end{array}$ \\
\hline 21 & $\begin{array}{l}\text { GOOGLE } \\
\text { ACADÊMI } \\
\text { CO }\end{array}$ & $\begin{array}{l}\text { A influência da família e } \\
\text { o papel do enfermeiro na } \\
\text { promoção do aleitamento } \\
\text { materno. }\end{array}$ & $\begin{array}{l}\text { Bullon et al., } \\
2009 .\end{array}$ & $\begin{array}{l}\text { Discorrer sobre o papel do } \\
\text { pai no aleitamento materno; } \\
\text { conhecer o papel da mulher- } \\
\text { avó neste período e } \\
\text { identificar a atuação do } \\
\text { profissional de enfermagem } \\
\text { neste contexto. }\end{array}$ & $\begin{array}{l}\text { O Aleitamento Materno (AM) favorece } \\
\text { o desenvolvimento da estrutura facial, } \\
\text { da mastigação, da fala e do alinhamento } \\
\text { dos dentes e respiração, além de reduzir } \\
\text { o risco das doenças crônicas como } \\
\text { diabetes, hipertensão e arteriosclerose. }\end{array}$ \\
\hline 22 & $\begin{array}{l}\text { GOOGLE } \\
\text { ACADÊMI } \\
\text { CO }\end{array}$ & $\begin{array}{ll}\text { A promoção } & \text { do } \\
\text { aleitamento materno na } & \\
\text { estratégia de saúde da } \\
\text { família. }\end{array}$ & $\begin{array}{l}\text { Battaus, } \\
\text { Liberali, } \\
2014 .\end{array}$ & $\begin{array}{l}\text { Demonstrar os aspectos } \\
\text { relacionados à promoção do } \\
\text { aleitamento materno na } \\
\text { Estratégia de Saúde da } \\
\text { Família (ESF). }\end{array}$ & $\begin{array}{l}\text { A promoção do aleitamento materno na } \\
\text { ESF demonstram a importância dessas } \\
\text { equipes na atuação junto às famílias } \\
\text { com o intuito de promoção da saúde e } \\
\text { uma prática extremamente importante } \\
\text { cujo objetivo é, entre tantos outros, } \\
\text { contribuir para a redução da } \\
\text { mortalidade infantil. }\end{array}$ \\
\hline 23 & $\begin{array}{l}\text { GOOGLE } \\
\text { ACADÊMI } \\
\text { CO }\end{array}$ & $\begin{array}{l}\text { Promoção do aleitamento } \\
\text { materno no contexto da } \\
\text { estratégia de saúde da } \\
\text { família. }\end{array}$ & $\begin{array}{l}\text { Costa et al., } \\
2019 .\end{array}$ & $\begin{array}{l}\text { Descrever a promoção da } \\
\text { saúde para o aleitamento } \\
\text { materno e refletir sobre sua } \\
\text { importância no espaço da } \\
\text { Estratégia de Saúde da } \\
\text { Família, onde os contatos } \\
\text { com a gestante são } \\
\text { oportunizados. }\end{array}$ & $\begin{array}{l}\text { O enfermeiro tem a oportunidade de } \\
\text { estreitar laços, educar e sensibilizar a } \\
\text { respeito das práticas de amamentação } \\
\text { no ambiente estudado, acolhendo suas } \\
\text { clientes, formando vínculos, } \\
\text { diminuindo inseguranças e promovendo } \\
\text { saúde. }\end{array}$ \\
\hline 24 & $\begin{array}{l}\text { GOOGLE } \\
\text { ACADÊMI } \\
\text { CO }\end{array}$ & $\begin{array}{l}\text { A atuação do (a) } \\
\text { enfermeiro (a) na } \\
\text { promoção, incentivo e } \\
\text { apoio ao aleitamento } \\
\text { materno. }\end{array}$ & $\begin{array}{c}\text { Marinho, } \\
\text { Andrade, } \\
\text { Abrão, } 2016 .\end{array}$ & $\begin{array}{l}\text { Analisar a atuação do (a) } \\
\text { enfermeiro (a) na } \\
\text { promoção, incentivo e apoio } \\
\text { ao aleitamento materno. }\end{array}$ & $\begin{array}{l}\text { O enfermeiro (a) é o profissional mais } \\
\text { próximo das gestantes, detentor de } \\
\text { conhecimentos técnicos e científicos } \\
\text { que deve utilizar meios facilitadores de } \\
\text { educação em saúde na assistência direta } \\
\text { a essas mulheres e sua família, assim } \\
\text { como na comunidade. Dessa forma, o } \\
\text { (a) enfermeiro (a) torna-se uma peça } \\
\text { fundamental no processo de promoça,o, } \\
\text { incentivo e apoio do aleitamento } \\
\text { materno. }\end{array}$ \\
\hline 25 & $\begin{array}{l}\text { GOOGLE } \\
\text { ACADÊMI } \\
\text { CO }\end{array}$ & $\begin{array}{l}\text { Promoção do aleitamento } \\
\text { materno exclusivo na } \\
\text { visão dos profissionais de } \\
\text { uma Estratégia Saúde da } \\
\text { Família. }\end{array}$ & $\begin{array}{c}\text { Vieira et al., } \\
2020 .\end{array}$ & $\begin{array}{l}\text { Conhecer quais as } \\
\text { estratégias utilizadas pelos } \\
\text { profissionais para o } \\
\text { incentivo do aleitamento } \\
\text { materno exclusivo. }\end{array}$ & $\begin{array}{l}\text { Evidencia-se a necessidade de } \\
\text { potencializar o cuidado para gestantes e } \\
\text { nutrizes quanto a educação em saúde, } \\
\text { contemplando o manejo frente aos } \\
\text { desafios impostos pela amamentação. }\end{array}$ \\
\hline 26 & $\begin{array}{l}\text { GOOGLE } \\
\text { ACADÊMI } \\
\text { CO }\end{array}$ & $\begin{array}{l}\text { O papel do enfermeiro na } \\
\text { promoção ao aleitamento } \\
\text { materno. }\end{array}$ & $\begin{array}{l}\text { Brandão et } \\
\text { al., } 2011 .\end{array}$ & $\begin{array}{l}\text { Sintetizar o conhecimento } \\
\text { produzido sobre a } \\
\text { contribuição do profissional } \\
\text { enfermeiro na promoção e } \\
\text { apoio ao aleitamento } \\
\text { materno. }\end{array}$ & $\begin{array}{l}\text { O enfermeiro é o agente disseminador } \\
\text { da promoção ao aleitamento materno. } \\
\text { Destacam-se como suas atribuições a } \\
\text { comunicação, o acolhimento e o } \\
\text { processo educativo em saúde conduzido } \\
\text { a partir dos saberes e expectativas dos } \\
\text { sujeitos, como ferramentas empregadas } \\
\text { no intuito de promover o estímulo e a } \\
\text { adesão das mães à amamentação. }\end{array}$ \\
\hline
\end{tabular}




\begin{tabular}{|c|c|c|c|c|c|}
\hline 27 & $\begin{array}{l}\text { GOOGLE } \\
\text { ACADÊMI } \\
\text { CO }\end{array}$ & $\begin{array}{ll}\text { Assistência } & \text { de } \\
\text { enfermagem } & \text { na } \\
\text { manutenção } & \text { do } \\
\text { aleitamento materno. } & \end{array}$ & $\begin{array}{l}\text { Belemer, } \\
\text { Ferreira, } \\
\text { Oliveira, } \\
2018 .\end{array}$ & $\begin{array}{l}\text { ompreender as dimensões } \\
\text { da enfermagem na } \\
\text { manutenção do aleitamento } \\
\text { materno para evitar o } \\
\text { desmame precoce. }\end{array}$ & $\begin{array}{l}\text { As estratégias de incentivo ao } \\
\text { aleitamento materno têm um papel } \\
\text { importante na promoção e no apoio a } \\
\text { amamentação, mas é preciso o apoio } \\
\text { contínuo das unidades de saúde para } \\
\text { continuidade do AME até os seis } \\
\text { meses. Constatou-se a facilidade na } \\
\text { aplicação das estratégias possibilitando } \\
\text { uma ferramenta educativa de utilidade } \\
\text { na prática dos enfermeiros, sendo, } \\
\text { conveniente que os mesmos sejam } \\
\text { capacitados para implantarem tal } \\
\text { metodologia nas ações de educação em } \\
\text { saúde com mulheres no puerpério. }\end{array}$ \\
\hline 28 & LILACS & $\begin{array}{l}\text { Partejar de } \text { primíparas: } \\
\text { reflexos } \\
\text { amamentação. }\end{array}$ & $\begin{array}{c}\text { Castro et al., } \\
2019 .\end{array}$ & $\begin{array}{l}\text { Analisar, a partir da } \\
\text { experiência de primíparas, a } \\
\text { relação entre a assistência } \\
\text { recebida durante o parto } \\
\text { normal e o pós-parto } \\
\text { imediato e seus reflexos na } \\
\text { amamentação. }\end{array}$ & $\begin{array}{l}\text { Os anseios e particularidades de cada } \\
\text { puérpera precisam ser respeitados e } \\
\text { atendidos, valorizando o investimento } \\
\text { em políticas de saúde que enfatizem o } \\
\text { cuidado humanizado para cada mulher. } \\
\text { Logo, a educação em saúde precisa } \\
\text { estabelecer reflexão, discussão e } \\
\text { aprendizado nesse processo que } \\
\text { transcende o biológico. }\end{array}$ \\
\hline 29 & MEDLINE & $\begin{array}{l}\text { Ações do programa de } \\
\text { puerpério na atenção } \\
\text { primária. }\end{array}$ & $\begin{array}{c}\text { Baratieri, } \\
\text { Natal, } 2019 .\end{array}$ & $\begin{array}{l}\text { Sistematizar } \\
\text { conhecimento produzido } \\
\text { sobre as ações de programas } \\
\text { de atenção pós-parto no } \\
\text { âmbito da APS, tanto em } \\
\text { nível nacional, como } \\
\text { internacional. }\end{array}$ & $\begin{array}{l}\text { A VD é um importante momento para a } \\
\text { equipe de APS detectar mudanças } \\
\text { físicas e emocionais precocemente, } \\
\text { desenvolver ações educativas, } \\
\text { identificar riscos e vulnerabilidades da } \\
\text { família, estabelecer vínculo } \\
\text { profissional-usuário e potencializar a } \\
\text { proteção à saúde da mulher e da criança } \\
\text { no pós-parto. Também promover e } \\
\text { incentivar a prática do aleitamento } \\
\text { materno exclusivo. }\end{array}$ \\
\hline 30 & BDENF & $\begin{array}{l}\text { Cuidados e orientações } \\
\text { de enfermagem às } \\
\text { puérperas no alojamento } \\
\text { conjunto. }\end{array}$ & $\begin{array}{l}\text { Mercado et } \\
\text { al., } 2017 .\end{array}$ & $\begin{array}{l}\text { Verificar as orientações } \\
\text { prestadas pelo enfermeiro à } \\
\text { puérpera em Alojamento } \\
\text { Conjunto }(\mathrm{AC}) \text {. }\end{array}$ & $\begin{array}{l}\text { O enfermeiro deve exercer, juntamente } \\
\text { com outros profissionais da saúde, } \\
\text { ações concernentes ao cuidado voltado } \\
\text { para mãe e filho, sendo responsável, } \\
\text { principalmente, pela educação em } \\
\text { saúde no que se refere ao incentivo à } \\
\text { amamentação, aos cuidados com o } \\
\text { recém-nascido, esclarecimento de } \\
\text { dúvidas, além de apoio à puérpera e } \\
\text { recém-nascido e orientação quanto às } \\
\text { consultas de crescimento e } \\
\text { desenvolvimento, vacinação e } \\
\text { planejamento familiar. }\end{array}$ \\
\hline 31 & $\begin{array}{l}\text { GOOGLE } \\
\text { ACADÊMI } \\
\text { CO }\end{array}$ & $\begin{array}{l}\text { Percepção das puérperas } \\
\text { acerca das orientações de } \\
\text { enfermagem quanto ao } \\
\text { aleitamento materno. }\end{array}$ & $\begin{array}{c}\text { Lopes et al., } \\
2020 .\end{array}$ & $\begin{array}{l}\text { Conhecer a percepção das } \\
\text { puérperas acerca das } \\
\text { orientações da equipe de } \\
\text { enfermagem quanto ao } \\
\text { aleitamento materno no pré- } \\
\text { natal e pós-parto imediato. }\end{array}$ & $\begin{array}{l}\text { A conduta do profissional de } \\
\text { enfermagem relacionado à } \\
\text { amamentação tem como finalidade } \\
\text { orientar, esclarecer dúvidas, incentivar, } \\
\text { apoiar, além de principalmente ter } \\
\text { empatia por cada caso. }\end{array}$ \\
\hline 32 & $\begin{array}{l}\text { GOOGLE } \\
\text { ACADÊMI } \\
\text { CO }\end{array}$ & $\begin{array}{l}\text { Condutas do enfermeiro } \\
\text { na promoção da } \\
\text { manutenção r do } \\
\text { aleitamento materno } \\
\text { exclusivo nas } \\
\text { de puericultura }\end{array}$ & $\begin{array}{l}\text { Antunes et } \\
a l ., 2017 .\end{array}$ & $\begin{array}{l}\text { Identificar as evidências } \\
\text { disponíveis nos artigos } \\
\text { científicos acerca das } \\
\text { condutas dos enfermeiros } \\
\text { da atenção primária na } \\
\text { manutenção do aleitamento } \\
\text { materno exclusivo nas } \\
\text { consultas de puericultura } \\
\end{array}$ & $\begin{array}{l}\text { O enfermeiro que realiza orientações } \\
\text { sobre amamentação e intercorrências } \\
\text { mamárias desmitifica os mitos sobre } \\
\text { amamentação e desenvolve atividades } \\
\text { de educação em saúde, promovendo a } \\
\text { manutenção do Aleitamento Materno } \\
\text { Exclusivo nas consultas de puericultura. }\end{array}$ \\
\hline
\end{tabular}


Research, Society and Development, v. 10, n. 1, e32910111736, 2021

(CC BY 4.0) | ISSN 2525-3409 | DOI: http://dx.doi.org/10.33448/rsd-v10i1.11736

\begin{tabular}{|c|c|c|c|c|c|}
\hline 33 & $\begin{array}{l}\text { GOOGLE } \\
\text { ACADÊMI } \\
\text { CO }\end{array}$ & $\begin{array}{l}\text { Contribuições } \\
\text { enfermeiro para a } \\
\text { promoção do aleitamento } \\
\text { materno }\end{array}$ & $\begin{array}{c}\text { Araújo et al., } \\
2020 .\end{array}$ & $\begin{array}{l}\text { Evidenciar a atuação do } \\
\text { Enfermeiro em ações } \\
\text { educativas, para promoção } \\
\text { ao aleitamento materno, e } \\
\text { os benefícios desta prática } \\
\text { efetiva, racidando } \\
\text { dificuldades encontradas } \\
\text { pelas mães durante a } \\
\text { lactação, bem como } \\
\text { descrever os riscos } \\
\text { inerentes, desencadeados } \\
\text { pelo desmame precoce para } \\
\text { o binômio mãe e filho. }\end{array}$ & $\begin{array}{l}\text { A prática de amamentar deve ser um } \\
\text { ato de prazer e dedicação garantindo os } \\
\text { benefícios oriundos desta prática para } \\
\text { mãe e filho, onde o enfermeiro deverá } \\
\text { estimular a amamentação e oferecer } \\
\text { apoio emocional frente às dificuldades } \\
\text { que podem surgir. A eficácia do AM } \\
\text { tem correlação direta com o } \\
\text { esclarecimento contextualizado das } \\
\text { dúvidas da nutriz e da família. }\end{array}$ \\
\hline
\end{tabular}

Fonte: Dados da pesquisa (2020).

No Quadro 1, tem-se a apresentação dos artigos selecionados para o estudo conforme número do artigo, base de dados, título, objetivo e conclusões importantes, com a finalidade de facilitar o desenvolvimento da discussão. A partir do estudo dos artigos estabeleceram-se discussões relevantes para observações das produções científicas relacionadas à pesquisa.

No gráfico representado abaixo caracteriza a distribuição de periódicos e a quantidade de artigos publicados, com a finalidade de facilitar a discussão das evidências encontradas na seleção da amostra final utilizada na elaboração do referido estudo. 
Research, Society and Development, v. 10, n. 1, e32910111736, 2021

(CC BY 4.0) | ISSN 2525-3409 | DOI: http://dx.doi.org/10.33448/rsd-v10i1.11736

Gráfico 1. Distribuição dos artigos conforme periódico e quantidade.

Brazilian Journal of Health Review Rev Enferm UFPE Online Ciência \& Saúde Coletiva

Revista de Enfermagem UERJ Revista de Atenão a Saúde

Revista de Iniciação Científica da UFRGN Rev. Rede de Cuid. Saúde Revista de Saúde Pública

Revista de Enfermagem da UFSM

Revista de Saúde Dom Alberto

Disciplinarum Scientia Saúde Research, Society and Development Revista de APS

Universus: Ciência da Saúde Atlante Cuadernos de Educación y Desarrollo Revista Enfermagem Conteporânia Periódicos

Revista Interfaces: Saúde, Humanas e...

Revista Eletrônica da Estácio Recife Revista da Rede de Enfermagem do Nordesde Revista Brasileira de Enfermagem Tempus Actas de Saúde Coletiva Saúde em Debate Perspectivas Online Revista Expressão da Estácio Revista de Ciência da Saúde Revista Conexção Eletrônica Escola Anna Nery Revistade de Enfermagem E-Scientia

Revista Brasileira de Saúde Funcional Cogitare Enfermagem

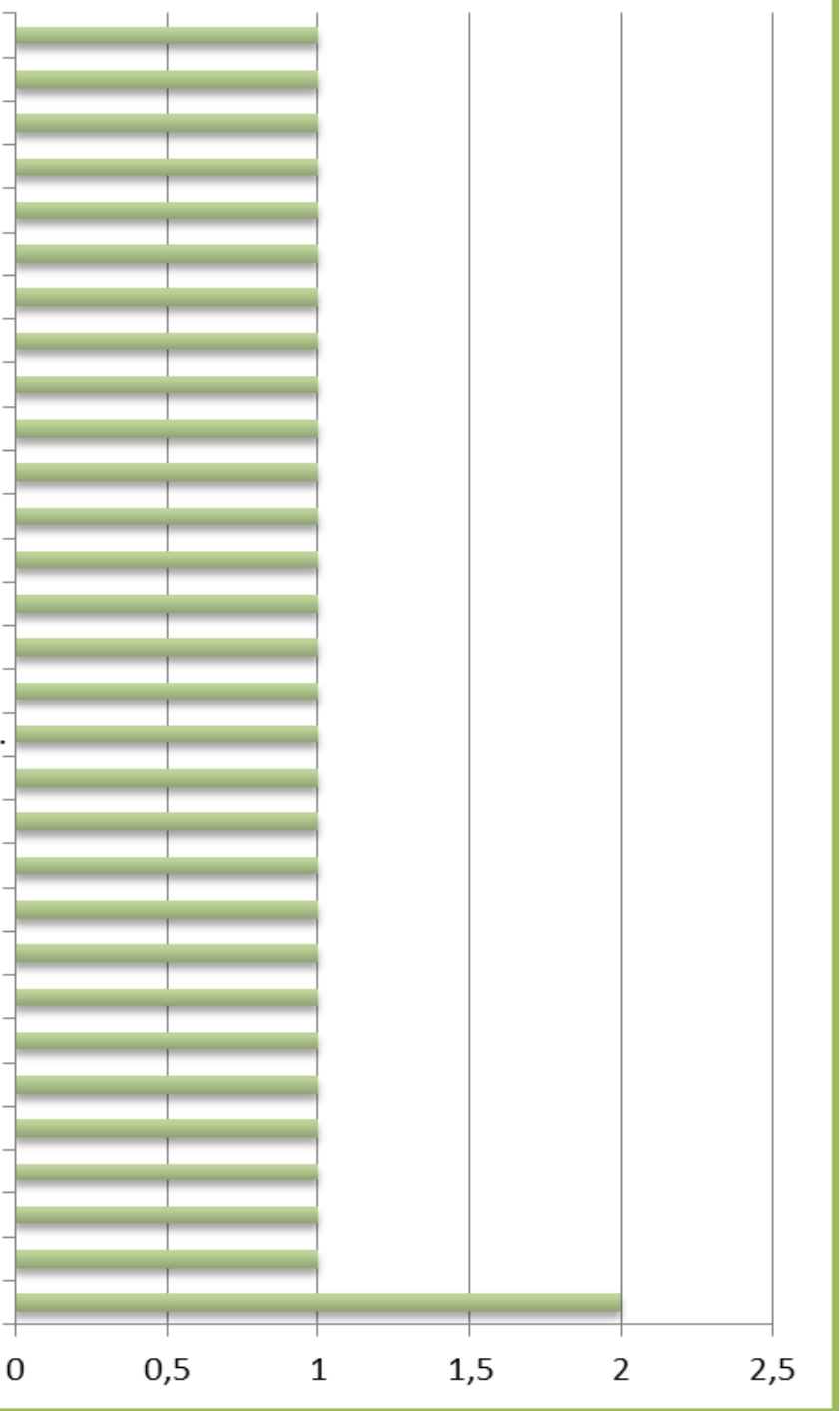

\section{$\uparrow$}

\section{Quantidade}

Fonte: Dados da pesquisa (2020).

De acordo com o gráfico ilustrado acima percebi-se a distribuição dos períódicos e da quantidade de artigos publicados, contidos na amostra final do presente estudo, identifica-se que a revista Cogitare Enfermagem publicou (2) artigos, Revista Brasileira de Saúde Funcional (1), E-Scientia (1), Escola Anna Nery Revista de Enfermagem (1), Revista Conexção Eletrônica (1), Revista de Ciência da Saùde (1), Revista Expresão da Estácio (1), Perspectivas Online (1), Saúde em Debate (1), Tempus Actas de Saúde Coletiva (1), Revista Brasileira Interdisciplinar de Saúde (1), Revista Brasileira de Enfermagem (1), Revista da Rede de Enfermagem do Nordesde (1), Revista Eletrônica da Estácio Recife (1), Revista Interfaces: Saúde, Humanas e Tecnologia (1), Revista de Enfermagem Conteporânea (1), Atlante Cuadernos de Educación y Desarrollo (1), Universus: Ciência da Saúde (1), Revista de APS (1), Research, Society and Development (1), Disciplinarum Scientia Saúde (1), Revista de Saúde Dom Alberto (1), Revista de Enfermagem da UFSM (1), Revista de Saúde Pública (1), Rev Rede Cuid. Saúde (1), Revista de Iniciação Científica da UFRGN (1), Revista de Atenção a Saúde (1), Revista de Enfermagem UERJ (1), Ciência \& Saúde Coletiva (1), Rev Enferm UFPE Online (1), Brazilian Journal Of Development (1), Brazilian Journal Of 
Research, Society and Development, v. 10, n. 1, e32910111736, 2021

(CC BY 4.0) | ISSN 2525-3409 | DOI: http://dx.doi.org/10.33448/rsd-v10i1.11736

Health Review (1), chegando a um resultado final de 33 artigos para serem trabalhados na elaboração do estudo. Sendo que foram adotados os criérios de inclusão e exclusão dos artigos selecionados para compor a construção do referido estudo, seguindo os aspectos metodológicos na elaborração da pesquisa.

Gráfico 2. Distribuição dos artigos conforme ano de publicação e quantidade.

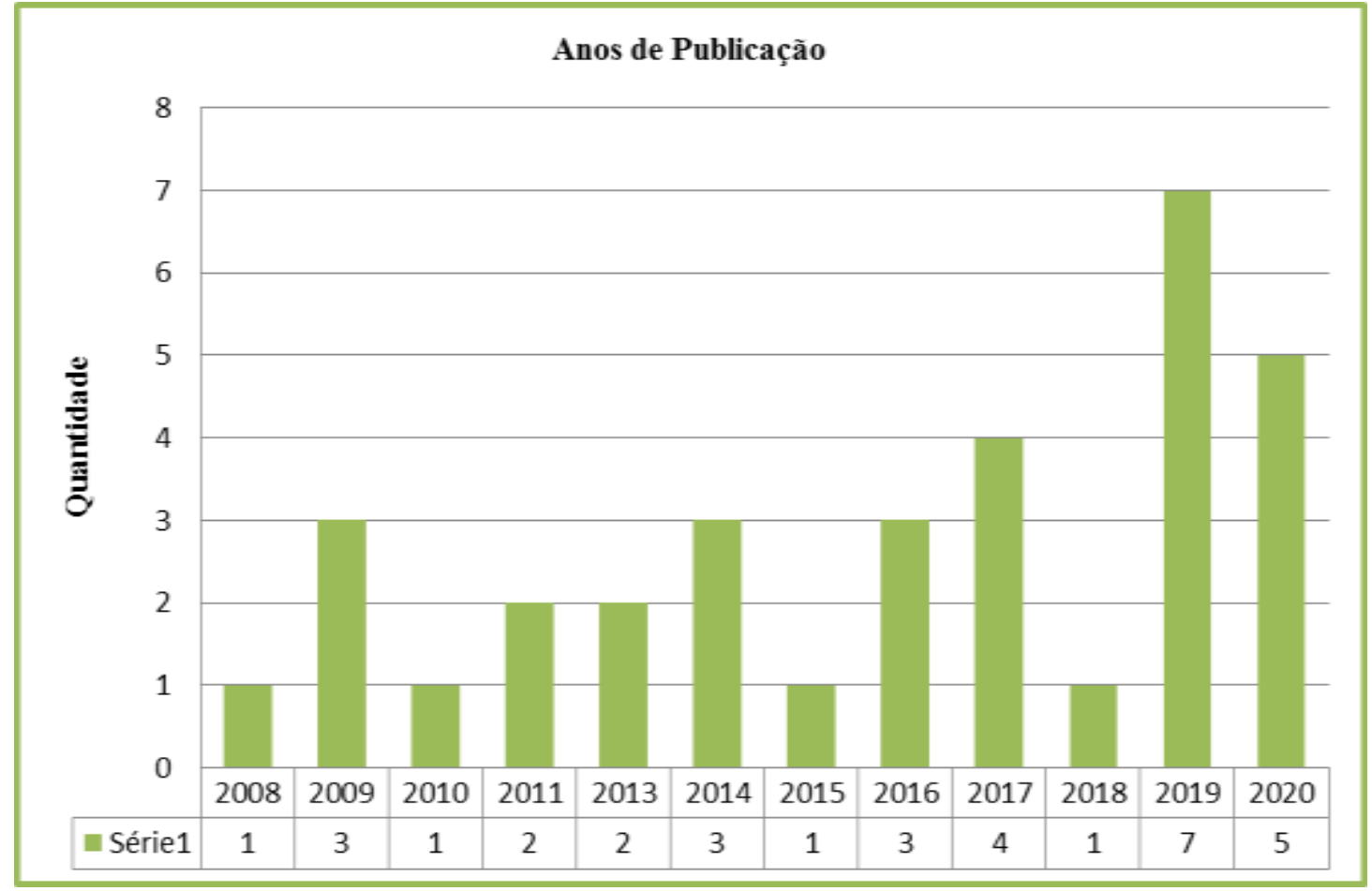

Fonte: Dados da pesquisa (2020).

Observa-se no gráfico acima, os anos e a quantidade de publicações que ocorreram na amostra final do presente estudo, analisa-se que no ano de 2008 houve (1) publicação, 2009 (3), 2010 (1), 2011 (2) 2013 (2), 2014 (3), 2015 (1), 2016 (3), 2017 (4), 2018 (1), 2019 (7), 2020 (5). Desse modo, totalizando no geral 33 artigos para compor a formação do presente estudo. 
Gráfico 3. Distribuição dos artigos segundo o ano de publicação e porcentagem.

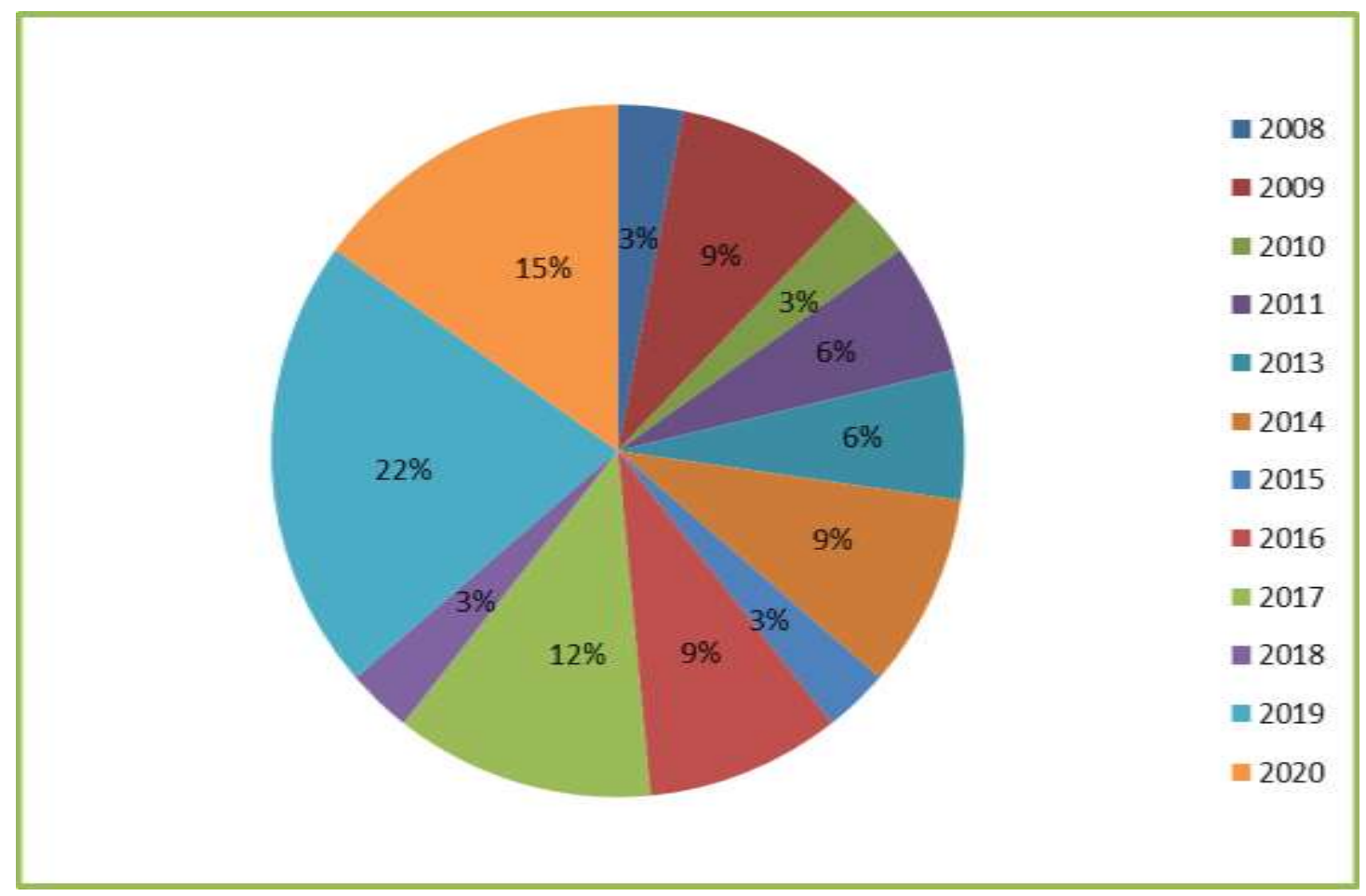

Fonte: Dados da pesquisa (2020).

Verifica-se no gráfico acima, a distribuição de anos e porcentagens de publicações correspondentes a amostra fial do presente estudo, constata-se que no ano de 2008 ocorreu (3\%) dos artigos publicados, 2009 (9\%), 2010 (3\%), 2011 (6\%) 2013 (6\%), 2014 (9\%), 2015 (3\%), 2016 (9\%), 2017 (12\%), 2018 (3\%), 2019 (22\%), 2020 (15\%). Dessa forma, alcançando 100\% dos artigos para compor o presente estudo.

\section{A importância do Aleitamento Materno Exclusivo e os benefícios para a criança e a mãe.}

A importância do aleitamento materno tem sido internacionalmente enfatizada em diversos documentos da Organização Mundial de Saúde - OMS que recomendam o aleitamento materno exclusivo por seis meses de vida. Baseados nessas evidências científicas dos benefícios do aleitamento materno exclusivo, muitos países, dentre eles o Brasil, assumiram oficialmente a recomendação de alimentos complementares após os seis meses de idade (Amorim, \& Andrade, 2019).

A prática do aleitamento materno está relacionada a fatores de ordem física, psicológica e social, sendo reconhecida a influência dos profissionais de saúde envolvidos neste processo. Essa ferramenta é apontada como prevenção de mais de 6 milhões de mortes em crianças menores de 12 meses, a cada ano. Se a amamentação fosse praticada universalmente, mais de 2 milhões de mortes poderiam ser evitadas (Batista, Farias, \& Melo, 2013).

O aleitamento materno é importante para a saúde do bebê e da mãe, sendo um ato que potencializa benefícios para ambos. A amamentação promove o estabelecimento de uma ligação emocional, muito forte e precoce, entre a mãe e a criança, além de fornecer uma dieta adequada para o recém-nascido, embora muitas crianças no mundo não cresçam e se desenvolvam adequadamente por dificuldades no aleitamento materno exclusivo. A amamentação vai para além de uma alimentação ideal ao bebê, pois se constitui como uma fonte de nutrientes essencial para o peso adequado e crescimento em altura. Ainda como benefício, contém componentes imunologicamente ativos que podem prevenir doenças infecciosas agudas e crônico- 
degenerativas na idade adulta. Verifica-se também o fortalecimento do vínculo afetivo mãe-filho nesta relação (Ferreira Junior et al., 2016).

O AME é fundamental para a saúde do bebê, pois oferta tudo o que é necessário para o bom crescimento e desenvolvimento deste. A promoção do AME deve estar inserida no rol das ações prioritárias da saúde do binômio mãe/bebê, pois esta prática proporciona mais saúde a criança, além de funcionar como uma vacina natural, não apresentando nenhum risco de contaminação ao bebê tem função de estimulação, ou seja, quanto mais a criança mamar, mais leite será produzido pela mãe (Lustosa, \& Lima, 2020).

A amamentação proporciona um desenvolvimento craniofacial do filho por meio dos movimentos da musculatura oral, através da sucção, respiração, e deglutição corretas, evitando problemas articulatórios e de hipodesenvolvimento, realiza uma interação de afeto físico, pele a pele prevenindo a hipotermia nas suas primeiras horas de vida. O processo de amamentar previne também a mãe a hipertensão, diabetes, colesterol e obesidade, além do câncer de mama e ovário, reduz o sangramento pós-parto e anemia, atua como coadjuvante em uma nova gestação e tem baixo custo financeiro para família. As vantagens da amamentação para a genitora e o lactente, são relatadas nas condutas que devem ser cumpridas instantaneamente logo após o parto, trazendo para a genitora benefícios como a redução da ansiedade, osteoporose, depressão e artrite reumatoide (Barroso, \& Alves, 2020).

A amamentação deve ser vivida como algo prazeroso pela mulher e, em vista disso, é de extrema importância ressaltar a participação da enfermagem em ações e programas voltados à promoção do aleitamento materno. A equipe de enfermagem é essencial neste processo e tem a responsabilidade de apoiar as mulheres e suas famílias por meio de ações que possam influenciar positivamente no sucesso da amamentação, evitando possíveis problemas (Silva, Waterkemper, Silva, Cordova, \& Bonilha, 2014).

A prática do aleitamento materno não se restringe apenas ao binômio mãe e filho, mas possui consequências a nível de sociedade, pois uma vez a criança adequadamente nutrida tem-se repercussões na redução dos índices de morbimortalidade neonatal e infantil. Além de benefícios para o lactente, o AM traz aspectos de interesse para a mulher, tais como o aumento do espaçamento entre as gestações, desde que a mulher se mantenha amenorréica e a amamentação seja praticada sobre livre demanda; redução do sangramento pós-parto, em virtude da contração uterina; diminuição da ocorrência de anemias e redução dos índices de câncer de ovário e mama (Azevedo et al., 2010).

O aleitamento materno é um dos pilares para a promoção e proteção de saúde das crianças em todo o mundo. Existe, portanto, um consenso a nível cívico, político, social e entre os profissionais de saúde, relativamente à importância do aleitamento materno para mães, filhos e sociedade. Dessa forma, é necessário orientar, intervir, promover e estimular o aleitamento materno, para que as puérperas estejam preparadas para realizar o aleitamento livre de problemas (Barbosa, \& Reis, 2020).

A amamentação promove o desenvolvimento saudável da criança, previne infecções gastrointestinais e respiratórias, reduz o risco de morbimortalidade infantil, diminui a incidência de alergias, entre outros. Além dessas vantagens, o aleitamento materno ajuda no desenvolvimento cognitivo e contribui para aumentar o vínculo entre a mãe e o filho (Alencar $e t$ al., 2019).

Os profissionais de saúde têm uma função relevante na promoção do aleitamento materno, atuando no incentivo e manejo da prática para amamentar. O sucesso da amamentação ocorre através de uma relação harmoniosa do enfermeiro e gestante, assim o papel primordial do enfermeiro é esclarecer as dúvidas sobre importância da amamentação exclusiva, ademais auxiliar nas possíveis dificuldades que venha a enfrentar. As ações de incentivo, promoção e apoio ao aleitamento materno devem ocorrer no conjunto das atividades dos profissionais, durante o pré-natal, o pré-parto, o nascimento, assim como nas imunizações, teste do pezinho e retorno para a consulta de puerpério (Alencar et al., 2019). 
O enfermeiro da equipe de saúde tem um importante papel frente à amamentação, pois são eles quem mais se relaciona com a mulher durante o ciclo gravídico-puerperal, lidando com as demandas do aleitamento, e são por meio de suas práticas que elas podem incentivar a amamentação e apoiar as gestantes, melhorando assim, os índices de aleitamento materno e, consequentemente, diminuindo os índices de desnutrição infantil, alergias, anemias, doenças dentárias e infecções que podem elevar à mortalidade infantil, além de diminuir as internações, custos com consultas, medicamentos e outros (Marinho, Andrade, \& Abrão, 2016).

\section{A atuação do enfermeiro nas ações de educação em saúde sobre o aleitamento materno}

O profissional de enfermagem deve tranquilizar a puérpera, exercendo o papel de esclarecer sobre os aspectos fisiológicos e anatômicos da amamentação e destacar a região areolar e mamilar como partes importantes no processo de sucção executado pelo RN. A falta de conhecimento técnico científico e de orientações a respeito da amamentação é um dos principais fatores de risco para o desmame precoce (Lustosa, \& Lima, 2020).

A assistência de enfermagem deve ser prestada com orientações em como realizar a amamentação com técnica adequada, posição e pegada correta; deve prestar informação com relação aos cuidados que devem ser tomados com os mamilos para mantê-los secos, orientar a necessidade de fazer exposição ao ar livre ou luz solar e realizar trocas frequentes dos forros usados quando ocorrer o vazamento de leite; ter o cuidado para não usar produtos que retirem a proteção natural do mamilo, como álcool, sabão ou qualquer produto secante; não ter restrições ao colocar a criança para mamar; também de ser realizadas explicações de como evitar ingurgitamento mamário e de como aumentar a flexibilidade da aréola através da ordenha manual antes de colocar a bebê para mamar, caso esta apresentar-se ingurgitada, assim contribuindo para pegada adequada, ser esclarecido que não use protetores de mamilos, pois eles, além de não serem eficazes podem causar ou serem responsáveis pelo trauma mamilar. E vale deixar claro que fazer restrição durante a amamentação não irá ter prevenção ou tratamento do trauma mamilar (Lustosa, \& Lima, 2020).

A enfermagem tem papel fundamental no que tange a amamentação e atua em várias etapas como: Anamnese e exame físico, onde o enfermeiro coleta todos os dados da paciente; busca informações familiares e econômicas; diagnostico de enfermagem, o enfermeiro analisa os dados coletados para determinar o diagnostico e planejamento, o enfermeiro desenvolve um plano de cuidados e prescreve intervenções para a obtenção dos resultados esperados; implementação, o enfermeiro avalia o progresso da paciente na obtenção dos resultados (Carvalho, Carvalho, \& Magalhães, 2011).

O profissional de enfermagem atua nas orientações sobre o posicionamento do bebê no momento da amamentação, para estabelecer correta capacidade de sucção; falar sobre a importância de estar em um ambiente tranquilo e calmo na hora de realizar a mamada, também prestar informações sobre o revezamento dos seios, e frequência das mamadas (demanda livre); sempre esclarecer a mãe sobre a introdução de outro tipo de alimento na dieta do bebê após os seis primeiros meses de vida (Ferreira, Lima, Coelho, Grilo, \& Gonçalves, 2016).

As atividades de educação em saúde, principalmente, as realizadas em grupo, são recursos que permitem a aproximação entre profissionais de saúde e a população contribuindo para o oferecimento de uma assistência humanizada e qualificada, pois ocorre a partir das interações entre seres humanos de forma dinâmica e reflexiva. A técnica de trabalho em grupo promove o fortalecimento das potencialidades individuais e grupais, a valorização da saúde, a utilização dos recursos disponíveis e o exercício da cidadania sendo ferramentas importantes no desenvolvimento das práticas educativas em saúde (Barbosa, Santos, Moraes, Rizzardi, \& Corrêa, 2015).

Neste contexto, a educação em saúde pode ser um instrumento indispensável, pois permite desenvolver atividades direcionadas aos princípios de educar, facilitando, com isso, a sensibilização das mães para a tomada de consciência destes 
valores. Para que isso ocorra se faz necessário que a mulher conheça o seu próprio corpo, pois com isso ela pode desenvolver sua autonomia e empoderamento (Barbosa, Santos, Moraes, Rizzardi, \& Corrêa, 2015).

O profissional de saúde deve identificar durante o pré-natal os conhecimentos, a experiência prática, as crenças e a vivência social e familiar da gestante a fim de promover educação em saúde para o aleitamento materno, assim como, garantir a vigilância e a efetividade durante a assistência a nutriz no pós-parto. É necessário que o enfermeiro acompanhe a mãe e informe sobre os problemas mais frequentes que podem surgir na hora da amamentação, como: fissura ou rachaduras, leite empedrado ou peito ingurgitado, mastite facilitando assim o processo de amamentação, e diminuindo as taxas de desmame precoce (Barbosa, Santos, Moraes, Rizzardi, \& Corrêa, 2015).

O suporte profissional é capaz de influenciar a mulher na decisão para amamentar. O aleitamento materno, embora seja um ato natural, tem sua prática permeada por desafios e dificuldades, justificando a necessidade de explorar o apoio técnico e emocional oferecido para o sucesso da amamentação. As orientações e intervenções de educação em saúde nos diferentes períodos pré-parto e pós-parto são efetivas para o aumento do início e duração do AME, isolados ou em combinação, e podem estar associados ao suporte interpessoal e familiar. É necessário estabelecer uma comunicação eficiente entre o profissional de saúde e a nutriz para apoio na decisão de amamentar, que deve ir além do desenvolvimento de competências e habilidades técnicas (Baue, Ferrari, Cardelli, \& Higarashi, 2019).

O profissional de saúde, em especial o enfermeiro, deve sistematizar a prática clínica da amamentação, considerando as necessidades das mulheres lactantes, e utilizar ferramentas fundamentais, tais como: a comunicação, o diagnóstico de enfermagem e intervenções adequadas para incentivar e manter o aleitamento materno, evitando dificuldades, dúvidas e possíveis complicações, como o desmame precoce (Baue, Ferrari, Cardelli, \& Higarashi, 2019).

O enfermeiro deve identificar as oportunidades que podem assegurar a educação sobre a prática de amamentação, dentro de um diagnóstico precoce e um tratamento a tempo adequado, contribuindo com o desenvolvimento populacional, não somente em uma prestação de assistência, mas também na promoção e educação a saúde (Costa, Queiroz, Queiroz, Ribeiro, \& Fonseca, 2013).

A enfermagem neste momento entra como o reconhecedor dos processos que podem dificultar a amamentação da criança, sendo de grande consequência para a mãe e para a criança. Assim, a enfermagem contribui com a orientação e esclarecimentos integrados, humanizados e com respeito, ajudando na superação de inseguranças, dificuldades e formação familiar. O enfermeiro na assistência ao puerpério e puericultura deve conscientizar as mães quanto à responsabilidade de amamentar e o quanto este ato traz benefícios para ela e o bebê. Nesta relação enfermeiro-mãe, deve-se traçar um planejamento de cuidados onde o foco é a saúde de ambos (mãe e filho) mostrando especialmente a mãe o leite materno é fundamental para a vida do bebê (Costa, Queiroz, Queiroz, Ribeiro, \& Fonseca, 2013).

A enfermagem deve realizar um acompanhamento perante as mães que se encontram em dificuldades, as consultas de enfermagem devem existir como orientação, realização de ajuda das necessidades, atuação e atenção especial, integração e apresentando de dúvidas e formas melhores para se dar com esta nova realidade para mãe. Além disso, o enfermeiro pode sanar as dúvidas, ensinar como amamentar, desmistificar medos, e ajudar a mãe a compreender o seu papel nesta fase importante de vida do bebê. Para tanto é necessário que o enfermeiro busque interagir com esta mulher, conhecer as dificuldades da mesma e informá-la sobre a importância de adotar uma prática saudável de aleitamento materno. Desta forma, o profissional precisa estar preparado para prestar uma assistência solidária, integral e eficaz, respeitando o saber, a história de vida de cada mulher para que esta possa superar seus medos, dificuldades e inseguranças (Costa, Queiroz, Queiroz, Ribeiro, \& Fonseca, 2013).

O enfermeiro no puerpério é o profissional mais envolvido em educar a puérpera acerca da alimentação mais adequada durante o aleitamento, dos exercícios que permitem a melhor ejeção de leite e da adoção de fatores ambientais que 
influenciem positivamente a implementação de uma experiência ímpar, saudável e prazerosa, durante a amamentação (Bullon, Cardoso, Peixoto, \& Miranda, 2009).

A promoção da saúde, por meio de práticas educativas, é fundamental na política de saúde. Assim, a promoção do aleitamento materno é questão fundamental das políticas públicas voltadas à qualidade de vida materno-infantil. A implementação de ações voltadas a essa questão é um desafio para o sistema de saúde, numa perspectiva de abordagem integral e humanizada, uma vez que envolve ações coletivas e intersetoriais (Battaus, \& Liberali, 2014).

A Atenção Primária à Saúde visa à promoção do AM, com ações de educação em saúde, levando conhecimento, orientações e empoderamento da mulher a está prática, sendo o nível de atenção que, está mais em contato com os indivíduos e famílias, mudando o modelo assistencial e preenchendo todas as condições de promoção, apoio e proteção a amamentação. A atuação da equipe de enfermagem, diante da complexa prática da amamentação, deve estar preparada para os indícios que as puérperas precisam de apoio, orientações e cuidados. As práticas de educação em saúde são primordiais para que as dificuldades e necessidades detectadas durante a amamentação sejam passíveis de intervenção e planejadas estratégias para que as dificuldades sejam superadas (Vieira, Freitas, Zanon, \& Anversa, 2020).

O enfermeiro, a nutriz e sua família, construam valores sobre aleitamento materno, valorizando sua rede de apoio e incluindo-a nos programas de educação em saúde sobre o aleitamento materno. As atividades de educação em saúde podem revelar-se um espaço para compartilhar experiências, sentimentos e afetos, além da troca de conhecimentos técnico-científicos e empíricos. Assim como proporcionam às mulheres e suas famílias uma melhor compreensão de si, bem como de recursos para a saúde no âmbito individual e coletivo (Antunes, Costenaro, Diaz, \& Rangel, 2017).

\section{Conclusão}

Evidenciou-se no estudo, que a enfermagem tem grande importância na ampliação de estratégias para promover o aleitamento materno e auxiliar na desmistificação e na quebra desses paradigmas. Compete a ela a atribuição de garantir a cada mãe uma escuta ativa, de modo a tornar a amamentação um ato prazeroso. Nesse contexto, o enfermeiro assume o seu papel de educador, orientador e incentivador das práticas de aleitamento materno e, também, garantir a assistência multidisciplinar à mulher e à criança durante o primeiro ano de vida.

Nesse sentido, observou-se a importância da assistência de enfermagem no aleitamento, ofertando amparo às mães para se obter uma amamentação exclusiva nos primeiros seis meses de vida, dando o suporte que elas precisam nas dificuldades que podem ocorrer durante este processo, diminuindo, assim, o desmame precoce, evitando, destarte, impactos negativos no índice de mortalidade infantil e fortalecendo esse vínculo tão importante para mãe e filho que vai perdurar para o resto vida.

Portanto, espera-se que esse estudo possa contribuir para a comunidade acadêmica e cientifica, no sentido de aprimorar e desenvolver discussões relevantes sobre essa temática tão importante que deve ser trabalhada no cotidiano do enfermeiro e por toda a equipe de saúde. Torna-se importante a realização de estudos futuros que abordem essa questão, no intuito de ampliar a produção científica a respeito desse assunto, com a finalidade de melhorar significativamente a assistência prestada a esses pacientes.

\section{Referências}

Alencar, A. M. V., Feitosa, G. P., de Andrade Oliveira, G., de Sousa Nunes, M. B., da Silva, M. N., dos Santos Pereira, M. S. I., \& Medeiros, K. M. F. (2019). Criando laços de amor: a importância do aleitamento materno exclusivo. Revista Interfaces: Saúde, Humanas e Tecnologia, 7(1), 238 -243.

Amorim, M. M., \& de Andrade, E. R. (2009). Atuação do enfermeiro no PSF sobre aleitamento materno. Perspectivas Online 2007-2011, 3(9). 
Antunes, B. S., Costenaro, R. G. S., Diaz, C. M. G., \& Rangel, R. F. (2017). Condutas do enfermeiro na promoção da manutenção do aleitamento materno exclusivo nas consultas de puericultura. Disciplinarum Scientia| Saúde, 18(1), 85-98.

Araújo, G. B., Fernandes, A. B., de Oliveira, A. C. A., Gomes, E. G. R., Pereira, T. L., Oliveira, L. S., \& Abed, R. A. (2020). Contribuições do enfermeiro para a promoção do aleitamento materno/Contributions of the nurse for the promotion of breastfeeding. Brazilian Journal of Health Review, 3(3),

Azevedo, D. S., dos Reis, A. C. S., Freitas, L. V., Costa, P. B., da Costa Pinheiro, P. N., \& de Castro Damasceno, A. K. (2010). Conhecimento de primíparas sobre os benefícios do aleitamento materno. Revista da Rede de Enfermagem do Nordeste, 11(2), 53-62.

Baratieri, T., \& Natal, S. (2019). Ações do programa de puerpério na atenção primária: uma revisão integrativa. Ciência \& Saúde Coletiva, $24,4227-4238$.

Barbosa, D. F. R., \& dos Reis, R. P. (2020). O enfermeiro no incentivo ao aleitamento materno. Revista Eletrônica da Estácio Recife, 6(1).

Barbosa, L. N., dos Santos, N. C., de Moraes, M. A. M., Rizzardi, S. D., \& da Costa Corrêa, E. (2015). Prevalence of educational practices about exclusive breastfeeding (EBF) in Cuiabá-MT. Escola Anna Nery Revista de Enfermagem, 19(1), 147-153.

Barroso, Z. A., \& Alves, N. C. M. (2020). A importância da assistência do enfermeiro das práticas educativas no aleitamento materno.

Batista, K. R. D. A., Farias, M. D. C. A. D. D., \& Melo, W. D. S. N. D. (2013). Influência da assistência de enfermagem na prática da amamentação no puerpério imediato. Saúde em debate, 37(96), 130-138.

Battaus, M. R. B., \& Liberali, R. (2014). A promoção do aleitamento materno na estratégia de saúde da família-revisão sistemática. Revista de APS, 17(1).

Bauer, D. F. V., Ferrari, R. A. P., Cardelli, A. A. M., \& Higarashi, I. H. (2019). Orientação profissional e aleitamento materno exclusivo: um estudo de coorte. Cogitare Enfermagem, 24.

Belemer, L. C. C., Ferreira, W. F. D. S., \& de Oliveira, E. C. (2018). Assistência de enfermagem na manutenção do aleitamento materno. Revista de Atenção à Saúde, 16(58).

Brandão, I. C. A., Santos, J. Q., Lima, K. Y. N., Santos, A. D. B., \& Monteiro, A. I. (2011). O papel do enfermeiro na promoção ao aleitamento materno: uma revisão narrativa. Revista de Iniciação Científica da Universidade Federal do Rio Grande do Norte, 3(4), 1-4.

Brant, P. M. C., dos Santos Affonso, H., \& Vargas, L. C. (2009). Incentivo à amamentação exclusiva na perspectiva das puérperas. Cogitare Enfermagem, 14(3), 512-517.

Bullon, R. B., Cardoso, F. A., Peixoto, H. M., \& de Miranda, L. F. (2009). A influência da família e o papel do enfermeiro na promoção do aleitamento materno. Universitas: Ciências da Saúde, 7(2), 49-70.

Caldeira, A. P., Fagundes, G. C., \& Aguiar, G. N. D. (2008). Intervenção educacional em equipes do Programa de Saúde da Família para promoção da amamentação. Revista de Saúde Pública, 42, 1027-1233.

Carvalho, J. K. M., Carvalho, C. G., \& Magalhães, S. R. (2011). A importância da assistência de enfermagem no aleitamento materno. e-Scientia, 4(2), 11-20.

Castro, I. R., de Melo, M. C. P., de Morais, R. J. L., \& dos Santos, A. D. B. (2019). Partejar de primíparas: reflexos na amamentação. Revista Enfermagem UERJ, 27, 43354

Costa, F. D. S., Silva, J. L. L. D., Machado, E. A., Soares, L. M., Brezolin, C. A., \& Silva, J. V. L. (2019). Promoção do aleitamento materno no contexto da estratégia de saúde da família. Rev. Rede cuid. saúde, 44-58.

Costa, L. K. O., Queiroz, L. L. C., da Silva Queiroz, R. C. C., Ribeiro, T. S. F., \& Fonseca, M. D. S. S. (2013). Importância do aleitamento materno exclusivo: uma revisão sistemática da literatura. Revista de Ciências da Saúde, 15(1).

Deus Monteiro, A. K., \& Pereira, B. G. (2019). Enfermeiro como ator social incentivador do aleitamento materno. Revista de Saúde dom Alberto, 3(1), 62-76.

Ercole, F. F., Melo, L. D., \& Alcoforado, C. L. G. C. (2014). Revisão integrativa versus revisão sistemática Rev Min Enferm, 18(1), 9-12.

Ferreira, G. R., Lima, T. C. F., Coelho, N. M. D., Grilo, P. M. S., \& Gonçalves, R. Q. (2016). O papel da enfermagem na orientação do aleitamento materno exclusivo. Revista Conexão Eletrônica, 13(1), 1-18.

Junior, A. R. F., Rocha, F. A. A., Souza, M. T. A., Fontenele, F. M. C., Cavalcante, L. P. L., \& Vasconcelos, L. C. A. (2016). Cuidado de enfermagem no incentivo ao aleitamento materno exclusivo durante o pré-natal: Percepção de puérperas. Tempus Actas de Saúde Coletiva, 10(3), $19-29$.

Lustosa, E., \& Lima, R. N. (2020). Importância da enfermagem frente à assistência primária ao aleitamento materno exclusivo na atenção básica. Revista Brasileira Interdisciplinar de Saúde, 3(1).

Mendes, K. D. S., Silveira, R. C. D. C. P., \& Galvão, C. M. (2008). Revisão integrativa: método de pesquisa para a incorporação de evidências na saúde e na enfermagem. Texto \& contexto enfermagem, 17(4), 758-764.

Mercado, N. C., Souza, G. D. D. S., Silva, M. M. D. J., \& Anseloni, M. G. (2017). Cuidados e orientações de enfermagem às puérperas no alojamento conjunto. Rev. enferm. UFPE on line, 3508-3515.

Pereira, A. S., Shitsuka, D. M., Parreira, F. J., \& Shitsuka, R. (2018). Metodologia da pesquisa científica.

Prates, L. A., Schmalfuss, J. M., \& Lipinski, J. M. (2014). Amamentação: a influência familiar e o papel dos profissionais de saúde. Revista de Enfermagem da UFSM, 4(2), 359-367. 
Research, Society and Development, v. 10, n. 1, e32910111736, 2021 (CC BY 4.0) | ISSN 2525-3409 | DOI: http://dx.doi.org/10.33448/rsd-v10i1.11736

Santos Marinho, M., de Andrade, E. N., \& de Vilhena Abrão, A. C. F. (2016). A atuação do (a) enfermeiro (a) na promoção, incentivo e apoio ao aleitamento materno. Revista Enfermagem Contemporânea, 4(2).

Santos, E. A., Santos, S. S. D., \& Oliveira, A. D. C. C. D. (2019). A enfermagem e a orientação sobre aleitamento materno. Revista Expressão Da Estácio, 2(1).

Silva Lopes, A. A., de Souza Pereira, A., de Sousa Soares, T., de Nojosa Sombra, I. C., Casadevall, M. Q. D. F. C., de Sousa Castro, T., \& Bravo, L. G. (2020). Percepção das puérperas acerca das orientações de enfermagem quanto ao aleitamento materno. Brazilian Journal of Development, 6(7), 50581-50596.

Silva, N. M. D., Waterkemper, R., Silva, E. F. D., Cordova, F. P., \& Bonilha, A. L. D. L. (2014). Conhecimento de puérperas sobre amamentação exclusiva. Revista Brasileira de Enfermagem, 67(2), 290-295.

Siqueira, S. M. C., dos Santos, A. P. R., \& dos Santos, G. A. (2017). Ações desencadeadas pelo enfermeiro para promoção do aleitamento materno e prevenção do desmame precoce. Revista Brasileira de Saúde Funcional, 1(1), 56-56.

Sousa, L. M. M., Marques-Vieira, C. M. A., Severino, S. S. P., \& Antunes, A. V. (2017). A metodologia de revisão integrativa da literatura em enfermagem. $N^{o} 21$ Série 2-Novembro 2017, 17.

Souza, M. T. D., Silva, M. D. D., \& Carvalho, R. D. (2010). Revisão integrativa: o que é e como fazer. Einstein (São Paulo), 8(1), $102-106$.

Vieira, C. M., de Freitas, H. M. B., Zanon, B. P., \& Anversa, E. T. R. (2020). Promoção do aleitamento materno exclusivo na visão dos profissionais de uma Estratégia Saúde da Família. Research, Society and Development, 9(8), e796986355-e796986355. 